\title{
SWEET SPOTS OF RESIDUAL DETERRENCE: A RANDOMIZED CROSSOVER EXPERIMENT IN MINIMALIST POLICE PATROL
}

Geoffrey C. Barnes ${ }^{1,2} \mid$ Simon Williams $^{3} \mid$ Lawrence W. Sherman ${ }^{2} \mid$ Jesse Parmar $^{4} \mid$ Paul House $^{4}$ | Stephen A. Brown ${ }^{4}$

\author{
${ }^{1}$ London Metropolitan Police Service \\ ${ }^{2}$ University of Cambridge \\ ${ }^{3}$ New Zealand Police \\ ${ }^{4}$ Western Australia Police Force
}

Correspondence:

Geoffrey C. Barnes, University of Cambridge, gcb1002@ cam.ac.uk

Acknowledgements:

The authors are grateful to Commissioner Chris Dawson for his support of evidence-based policing in Western Australia, and specifically to Superintendent Brad Sorrell, Inspector Tara Doyle, and Senior Sergeant Glenn Spencer for their local leadership over the course of this experiment. The authors also wish to thank Jean McGloin, Christopher Koper, and David Keatly for their helpful comments on earlier drafts of this paper. 


\begin{abstract}
In this article, we examine how communities can maximize deterrence of crime while minimizing cost and police intrusion on public life. Using 3,720 hot spot-days, we show that the "sweet spot" duration of police absence, to maximize the residual deterrence of crime, was a full four days after the last day of targeting police patrol at each hot spot. Over a 248-day period, we randomly reshuffled 15 separate hot spots daily into either treatment (targeted police patrols) or control (no targeted patrols) for that day, so that all locations repeatedly switched between randomly assigned groups. This repeated crossover design (Cochrane \& Cox, 1957; Fienberg et al., 1980) included random periods of up to 20 consecutive days in which individual hot spots remained in the control condition, allowing us to measure how soon, and by what trajectory, the residual deterrent effect of targeted patrolling wore off. After four days without patrolling, there was a sudden termination of residual deterrence, marked by a $66 \%$ rise in offense frequency, and a $395 \%$ spike in our index of crime harm (House \& Neyroud 2018), compared to the treatment condition. It may be possible to deploy less, not more policing and still maximize deterrent effects.
\end{abstract}

\title{
KEYWORDS
}

crime harm index, deterrence, deterrence decay, GPS tracking, hot spots, police patrols, policing, residual deterrence

\section{1 | INTRODUCTION}

How little police patrol time is enough to deter crime in hot spots areas, long after police leave the area? While many studies have identified crime reduction benefits from more police time in hot spots (Braga et al., 2012; Koper, 1995), few studies have examined the possible deterrent effects of assigning less time. This gap is worth filling for reasons of both theory and policy.

For criminological theory, the gap lies in a broader question of how much residual deterrence can be produced in the periods when police are not present in a situation, as a follow-on effect from 
periods in which they are present (Dilmé \& Garrett, 2018; Koper et al., 2013; Nagin, 2013; Sherman, 1990; Sorg et al., 2013). That widely accepted definition of residual deterrence can be distinguished from what can be called the direct deterrence of crime by visible police presence when it is present. One recent study from the London Underground (Ariel et al., 2020) estimates that $97 \%$ of crimes prevented by extra patrol were averted through residual deterrence when police were not present, with only three percent of prevention effects attributable to direct deterrence during the hours when police were present.

For public policy, the gap in knowledge about residual deterrence is central to the debate about over-policing and under-policing, especially in neighborhoods suffering high conflict between police and minority groups. It is also important for understanding the trade-offs between reactive and proactive policing (Reiss, 1971), about which the link between research and policy remains central (National Academies of Sciences, 2018). Because targeted patrols of any kind fall squarely into the definition of proactive policing, research focusing on this tactic strikes at the core of the balance between protection and oppression in high-crime areas.

Developing a stronger empirical basis for both theory and policy about police patrol requires evidence of how patrol affects crime across a wide range of different dosages, other things equal. Three challenges to creating such evidence have limited its availability to date: more precise measurement of patrol time, controlled differences of many gradations of patrol dosage within a single study, and the appropriate counterfactuals challenge posed by Nagin \& Sampson (2019). The first challenge is fundamental, since only a handful of hot spots experiments have ever measured police presence at all (Ariel et al., 2016; Rosenfeld et al., 2014; Sherman \& Weisburd, 1995; Telep et al., 2014; Williams \& Coupe, 2017). The use of GPS tracking of officers in both treatment and control conditions is challenging, but may offer the greatest precision. Precision is arguably essential for discovering how little patrol is needed to deter crime in hot spots.

The second challenge is to test a wide range of differences in patrol dosage within the same study, so that the design may use random assignment to hold "other things equal" in any comparison 
of differential patrol time. This challenge requires experiments to make comparisons within a single study, rather than comparing experiments across cities in their average patrol dosage (as done by Ariel et al., 2020). Comparison of dosages across different communities with different baselines suffer too many other differences to be able to isolate the causal impact of patrol time, independent of the kinds and rates of crimes different police jurisdictions may face at different points in time. Thus even if there were 20 or 30 randomized trials of hot spot patrol increases - instead of just four to date (Ariel et al., 2020, p. 122, Table 7) - the question of how little patrol is needed to sustain deterrence could still not be answered clearly across trials.

A third challenge is the Nagin and Sampson (2019, p. 124) critique of parallel-track experiments, in which the design fails to create "counterfactual worlds" between experimental and control communities because all hot spots (or none) are given extra patrols. Short of randomly assigning a large sample of entire cities to different patrol strategies, they argue that no hot spots policing experiment comparing parallel tracks of control and treatment locations (e.g., Ratcliffe et al., 2011; Rosenfeld et al., 2014; Sherman \& Weisburd, 1995; Telep et al., 2014) can create externally valid estimates of what they (and economists) call "system-wide equilibrium effects." Specifying the entire system as the target, they claim that parallel tracks cannot eliminate the potential system-level feedback that the existence of control hot spots imposes on criminal behavior in treatment hot spots. Hence, research using such designs cannot generalize to a world in which all hot spots have higher (or lower) levels of patrols.

All three of these challenges can arguably be satisfied by experiments using a repeated crossover design, in which each hot spot becomes its own control (Cochrane \& Cox, 1957). This design was first suggested for patrol experiments a half-century ago, in the wake of the Kansas City Preventive Patrol Experiment (Fienberg et al., 1980). Yet as far as we know, a crossover design has been used in only one published hot spot patrol experiment (Williams \& Coupe, 2017), and even that study did not compare differences in total patrol time. In that experiment, every hot spot was targeted with a constant amount of patrol time (45 minutes) every day for 100 days, under two 
randomly-assigned conditions: nine short patrols of 5 minutes each versus three long patrols of 15 minutes each (long patrols were more effective, with total time almost identical). Thus no hot spots experiment to date has reported a true "counterfactual worlds" comparison of across a range of patrol dosage within the same sample of (little) worlds - let alone one with direct measurement of patrol time showing that counterfactuals were successfully held constant.

In the present experiment, we meet all three challenges to estimating how much less patrol can be provided in high-crime areas without causing major increases in crime frequency or severity. Our design uses each of 15 hot spots as their own controls. The analysis also uses a "big data" approach to GPS tracking in measuring the minutes of patrol presence actually delivered. The design succeeds in showing virtually no patrol on control days, although with somewhat more variability of patrolling on treatment days. It also compares crime levels after one, two, three, four and more days of continuous control status, up to 20 days of no targeted patrol - a wide range of variation in periods of police absence.

Most important for the Nagin and Sampson (2019) challenge to meet the "real gold standard" of independent counterfactuals, the design also arguably eliminates system-level feedback effects. All hot spots are studied as their own world, in various counterfactual conditions of the same world. Those conditions are linked directly to the question of how much difference the recency of patrol visits makes for crime in each hot spot on each day. Because none of the 15 hot spots served as controls for longer than the others, there is no basis for arguing that a system feedback problem challenges the external validity of the results. What was true of these hot spots in one city could well be true for other hot spots in the same city, as well as hot spots in other cities, barring differences in social context (Sampson et al., 2013).

What our design does not address is a different question from the time police are present or absent. The unaddressed question is whether any particular kinds of police activities in hot spots work better than others in reducing certain kinds of crime (e.g., Rosenfeld et al., 2014). Testing this important question has its own complex requirements. Calibrating the minimal presence (or 
maximum absence) of police, regardless of what they do in hot spots, is complex enough to merit its own test. Answering the "time absent" question also provides a clearer foundation for future repeated crossover experiments that answer questions about the effects of police doing different things when they are present.

The most logical first step in finding a threshold of "minimalist" patrol is random assignment of different intervals of time in between visible patrol presence - not just in hours, but in days which reflects the reality of low patrol dosage everywhere which exists in many communities. The focus on time when police are absent from hot spots helps to identify the minimum patrol dosage communities may find both acceptable and effective, in relation to the criminogenic effects of varying lengths of police absence - which is generally seen as a threat to general deterrence.

\section{2 | GENERAL DETERRENCE AND POLICING}

The central hypothesis of general deterrence is that an entire population's rate of crime will be affected by sanctions or threats of sanctions (Zimring \& Hawkins, 1973). In the case of police strikes (e.g., Makinen \& Takala, 1980), for example, massive increases in crime demonstrate a loss of general deterrence, on average, across the population. Yet all of that aggregated increase may come from only a small subset of the population. The central difficulty with the wide breadth of the general deterrence hypothesis is the differential manner in which sub-sections of the population may respond to the same sanction threats, or even perceive those threats differently in different locations. This differential has been demonstrated experimentally at the individual level for the specific deterrence of randomly assigned arrests for domestic abuse (Berk et al., 1992; Pate \& Hamilton, 1992; Sherman et al., 1992), as well as at the neighborhood level (Marciniak, 1995).

It therefore seems plausible that such differential response would also occur with other aggregations beyond the individual level. Measuring the effects of variations in sanction threats across very large populations, such as cities, may be confounded by conflicting directions of effect on different subgroups or areas. We can therefore enhance precision in our knowledge of general 
deterrence by aggregating upwards from tests in smaller population subsets, rather than vice versa. Given the concentration of most crime in micro-spatial areas (Sherman et al., 1989; Weisburd, 2015), those locations are a logical focus to advance our knowledge of general deterrence. They also provide an opportunity for assessing how long police can stay away from a high crime area without causing crime to rise.

The best-known finding of the hot spots policing literature may be Koper's (1995) curve, which found a longer period of deterrence after police leave a hot spot if they had spent more time at the location before they left. Koper's (1995) non-experimental, observational study of 24,813 hot spot patrol visits found a major difference in the length of residual deterrence, with the greatest length crime-free time (measured up to 30 minutes after patrols departed) following a police presence of 10-15 minutes in length. This important finding implied a minimum duration of 10-15 minutes of patrol to maximize residual deterrence. What it did not address, however, was the maximum time police could remain absent without triggering an increase in crime.

The importance of that issue is seen in what is perhaps the least-known finding of Koper's (1995) analysis: the extent to which most deterrence happens when police are not present. His evidence implies a far greater impact of police presence when police were not there than when they were. He derives this conclusion by using the traditional parallel-tracks design, comparing the 50 observed control hot spots to the 50 observed treatment hot spots. He uses the concept of residual deterrence to describe what happens when police were not present in the two different treatment groups:

"Previous analyses... (Koper, 1992) illustrate residual deterrence from the [Sherman and Weisburd (1995)] experiment in a very direct manner: they use a minute-based data file containing a record for each minute of observation at every hot spot. In minutes when police were not visibly present at the hot spots $(n=379,622)$, the proportion of minutes during which [any] disorder was occurring was 25 percent less in the experimental areas than in the control 
areas. For criminal disorders, this difference was 65 percent. Both differences were statistically significant, demonstrating that higher patrol levels in an area enhance deterrence not only during the extra time when police are visible but also when police are not present. This concept has not been tested explicitly by other patrol studies (Koper, 1995, p. 658).”

And as noted above, Ariel et al. (2020, p. 124) have recently confirmed Koper's finding in the London Underground experiment, in which $97 \%$ of the crime prevention effect of patrolling Underground station platforms occurred on and around the treated platforms when police were not there. This evidence provides a lens by which to examine more generally the concepts of residual deterrence and its "sweet spots" as a component of general deterrence.

\section{1 | Residual Deterrence and its "Sweet Spots"}

As the above evidence shows, two related concepts in deterrence theory are helpful to identify the lowest frequency of police presence that can still maintain a general deterrent effect. Those concepts are residual deterrence in general, and the "sweet spots" of residual deterrence in particular.

Residual deterrence is the period of time in which any sanction or threat continues to deter crime, once delivered with an initial deterrent effect, after that specific sanction or threat delivery has ceased. Sherman (1990) called residual deterrence a "free bonus" of continued deterrence, without any need for the publicly visible application of criminal sanctions or threats. Nagin $(1998$, p. 9) summarized residual deterrence broadly as, “... a crime suppression effect that extends beyond the intervention until offenders learn by experience or word of mouth that it is once again 'safe' to offend." The concept was demonstrated qualitatively with aspects of organized crime, as described in the classic ethnography of Boston street life, in which police crackdowns meant that gambling must stop for a period of a few weeks "until the heat is off" (Whyte, 1947, p. 131). Such patterns were also arguably tested (and falsified) by studies of executions that examined homicide rates in the first 7 to 14 days after each execution (e.g., Grogger, 1990). 
This concept of residual deterrence has been used in multiple studies, with results that range across varying lengths of time or no time at all (Dilmé \& Garrett, 2018; Koper, Taylor, \& Woods, 2013; Nagin, 2013; Sorg, Haberman, Ratcliffe, \& Groff, 2013). It is not a formal theory; it is simply a description of a pattern that has been observed in some cases but not others. When it occurs, it lacks any form of explanation by reference to a casual mechanism. One possibility may be the concept of "risk updating" by potential offenders (Anwar \& Loughran, 2011; Matsueda et al., 2006), but no evidence addressing that concept has been collected in tandem with observations of residual deterrence.

The basic question remains of what pattern such deterrence actually follows. Sherman (1990) implies a linear decay of deterrence as time elapses after the cessation of a sanction threat, such as after police leave a location. Yet too little evidence is available to assume that linearity is the only, or even predominant, pattern that can be observed in the decay of general deterrence. Rather than focusing on the rate of change, the more important question for minimalist policing is arguably the length of the residual deterrence period.

The "sweet spots" of residual deterrence are the maximum lengths of continuing deterrent effects revealed from tests of police backing off (Sherman, 1990). They can be defined more precisely as the point at which the optimum deterrence for the least investment of sanction threats can be found. That is exactly what the "Koper curve" did for 24,813 observations of police visits to hot spots (Koper, 1995).

His work echoed the concept of sweet spots in other fields. In the engineering of a tennis racquet or baseball bat (Brody, 1981; Cross, 1998), for example, the sweet spot of the netting or wood grain is the point of impact that imparts maximum speed to the ball. In the case of a minimal level of patrol, a sweet spot of residual deterrence is the amount or frequency of patrol that can yield the most residual deterrence per minute of patrol. It has even been demonstrated, quasiexperimentally, by a major reduction in patrol time that had no effect on crime in an area (Gibson et al., 2017). The identification of such a sweet spot can also be explored by varying the total time of 
patrol visits, the length of each patrol visit (Williams \& Coupe, 2017), or the length of intervals of time between visits of a similar length.

\subsection{Evidence for Residual Deterrence: Length and Trajectory}

The first quantitative demonstration of residual deterrence in policing was the Police Foundation's San Diego Field Interrogation Experiment (Boydstun, 1975). In that study, field interrogations (stop \& question) were completely eliminated from one patrol beat for nine months, while they were maintained at the existing level in a matched comparison precinct. The study provided the first clear evidence of residual deterrence, since the increase in crime followed the elimination of police stops rather slowly (and gradually). As Sherman (1990) noted, the initial crime total after the no-stops "backoff" period began was below the mean for the baseline period. By the second and third months, crime had risen by only 20 percent above the baseline mean. Not until the fourth month of "no stops" did the residual deterrence end, with crime counts suddenly doubling over the mean for the baseline period.

Ross (1982), along with others who studied drunk driving crackdowns, identified new evidence of residual deterrence in the aftermath of these offense-specific increases in risks of arrest. While they studied larger local contexts, such as entire police force areas, these quasi-experiments help to build the evidence about what happens after the crackdowns stop - and for how long. They were echoed by conceptually similar projects of intensified police enforcement against open-air drug markets (e.g., Kleiman, 1987). In total, reports on 18 police crackdowns comprised the evidence for Sherman's (1990) narrative review, of which only six studies provided the evidence that formalized the concept of residual deterrence. The length of residual deterrence across these studies varied widely.

The concept of residual deterrence embraces both the duration of a deterrent effect and its trajectory. The duration of residual impact from any particular sanction (or threat thereof) is defined by the period that continues without a return of crime to higher levels, provided that this time passes 
without reinforcement (or treatment contamination) by any new sanctions or threats. This latter point is what makes measuring maximum residual deterrence so difficult in observational studies, since interference from any new sanctions (left uncontrolled) could cut short the period of measurement following the last sanction or threat.

A second dimension of residual deterrence is its trajectory. In his original formulation based on quasi-experimental evaluations of police crackdowns, Sherman (1990) proposed different forms for his four related concepts of initial deterrence (immediately after police increase their intrusion), initial deterrence decay (while police continue to maintain their intrusion), residual deterrence (after police intrusion ends), and residual deterrence decay. His description of the initial deterrence effect was clearly a non-linear pattern, in which there is a sudden and sharp drop in offending. He also implied that all other changes were linear, with effects "gradually" decaying at a "slow" rate. Yet his case studies were few, and varied widely in the nature of both crime and police activity. In order to get a clearer view of whether the form of residual deterrence decay is linear or sudden, researchers need to find (or generate) multiple cases of nearly identical police intrusions, with comparable postintrusion periods of observation.

More recent studies were specifically designed to search for residual deterrence. They provide further evidence of deterrence effects lasting days or weeks after police leave the scene. In a randomized trial designed to measure residual deterrent effects, Sherman and colleagues (1995) reported that highly visible police raids on crack houses in residential neighborhoods of Kansas City (Missouri) produced a sharp reduction in crime on the block, relative to other blocks with crack houses that had not been raided (despite search warrants issued). The sharpest reduction lasted for 4 to 5 days, followed by pattern of gradual decay in the difference between crime frequency on the experimental and control blocks. This difference, with less crime persisting in the treatment group relative to control, was discernible for residual deterrence of at least 12 days.

Koper and his colleagues (2013) then randomly assigned two kinds of patrol in Mesa, Arizona to selected street segments to look for stolen vehicles, with and without an automatic license plate 
readers (LPRs). The study found that the manual checking of license plates required more time in the locations receiving the no-LPR condition when compared to the faster-moving patrols in the LPR areas. The more rapid patrol condition (with LPRs) had no residual deterrent effect after the experiment ended. The street segments receiving slower policing, on the other hand, had a surprising pattern: no initial deterrence was observed during a two-week intervention period (of one hour of patrol per day). Yet as soon as the slower patrolling stopped, a new two-week period of residual deterrence began for both auto thefts (75\% drop) and crimes against persons (49\%).

Using an advanced spatial statistics model, Weisburd and colleagues (2016) found a striking average effect of a single stop-question-frisk encounter on street segments in the Bronx, New York City, based on police and crime records in 2011. In a time when the city's hottest street segments had an average of over 1.7 crimes and 3.58 stop-frisk encounters per week, each street segment with only one such encounter had, on average, a crime-free period of up to four days after the single instance of stop and frisk. Obviously, the application of these single encounters could not be randomly assigned, and these findings could be conflated with the reasons why the police performed fewer stops in these locations than they did elsewhere. Nevertheless, the decay patterns seen after these stops are consistent with a residual deterrent effect that last for a few days before disappearing.

The most negative evidence on residual deterrence (Sorg et al., 2013), meanwhile, did not directly contradict these other studies; it simply used a much longer time frame. Following up on both 12-week and 22-week periods of enhanced patrolling in the Philadelphia Foot Patrol Experiment (Ratcliffe et al., 2011), Sorg and his colleagues found no evidence of continuing deterrence over a 3-month period after foot patrols stopped. This conclusion, however, cannot tell us whether there was some residual deterrence for one, two, five or 10 days after the foot patrols came to an end; no analyses for those time periods were reported. Yet even if there had been residual crime reductions during these relatively short time periods, they would have been lost within the remainder of the analysis's three-month follow-up period. 
While these studies all contribute to the evidence for the potential length of residual deterrence effects, few of them help us to understand the trajectories - the speed and declining effect sizes over time - at which these residual effects decay. That the effects of a single stop and frisk encounter may last five days (Weisburd et al., 2016) does not show the shape of the deterrence decay trajectory. That the effect of a police raid on a crack house decays in a fairly linear fashion over 12 days (Sherman et al., 1995) is interesting, but has not been replicated in other studies of raids or other enforcement actions. As Ariel and colleagues (2016, p. 284) observe, the perceived "certainty [of apprehension] may come and go by an on-off switch, rather than being a continuous linear increase or decrease." All possibilities can be subject to testing.

\subsection{How Minimal can Minimalist Patrol Be?}

Perhaps the best way to discover how minimal patrol can become requires what no randomized hot spots test has provided thus far: measuring the effect of delivering no directed patrols for days on end in ordinary hot spots policing. If repeated daily visits of at least ten minutes to hot spots can generate a baseline level of deterrence (Koper, 1995; Williams \& Coupe, 2017), that baseline may then be maintained on a residual basis for minutes, hours, or even days. How long a residual deterrent effect might last before crime goes up can only be discovered by allowing a period of time to pass after a routine police presence is reduced or discontinued. Both Koper et al. (2013) and Sherman and colleagues (1995) followed up parallel groups for at least two weeks, after which a residual effect from fairly intensive police activity ended. Yet neither of these studies examined that day-to-day routine of ordinary police patrol.

In this study, we use random assignment to vary the intervals of time without routine patrol. By holding "all else equal," at least to a large extent, we can provide sound causal inference about the number of days in which a hot spot can last, without a new patrol visit, until crime rises to the levels seen prior to the last visit by police. We do not suggest that this experiment provides a definitive answer to the question of how frequently patrols must return in order to keep crime down. 
We only suggest that in this first examination of the question, we are able to present enough evidence to call for replications in other communities and countries.

\section{3 |DATA \& METHODS}

\section{1 $\mid$ Setting}

Our experiment was conducted in collaboration with the Western Australia Police Force (WAPF), an agency of about 7,000 police officers and 2,000 civilians policing the world's largest single police agency jurisdiction. The agency has 154 police stations spread over 2.5 million square kilometers and a population of 2.6 million, of whom 2.0 million reside in the Perth metropolitan area. The present research was conducted a single suburban police district, one of the 35 such districts located within the metropolitan region.

According to the most recent Australian census in 2016, the population of this police district was nearly 48,000 people, which places it at the $35^{\text {th }}$ percentile of metropolitan police districts. Although only $2.3 \%$ of this population was made up of aboriginal ${ }^{1}$ Australians, the Western Australia criminal justice system features enormous disproportionality amongst this small portion of its overall population (Martin, 2017; Sizer \& van Smeerdijk, 2017), particularly among young people (Bower et al., 2018; Department of Corrective Services, 2016). The participating police district ranks in the $91^{\text {st }}$ percentile across the metropolitan region for its percentage of aboriginal representation, and in the $94^{\text {th }}$ percentile when only young aboriginals (i.e., under the age of 25 ) are considered, meaning that this area is central to the kinds of social concerns that drive these statewide disparities.

During the financial year in which this research took place, the participating district experienced 13,331 reported criminal offences, 1,660 of which were violent in nature. These values

\footnotetext{
${ }^{1}$ For the purposes of discussion, the term "aboriginal" should be understood to include both aboriginal Australians and Torres Straight Islanders, despite the fact that Torres Straight Islanders are not very prevalent in the Perth metropolitan areas.
} 
translate to rates of 278.2 overall offences per 1,000 population, and 34.6 violent offences per 1,000 population, which place the district at the $91^{\text {st }}$ and $97^{\text {th }}$ percentiles across the metropolitan region, respectively. Moreover, all of the remaining districts with higher rates are either central business areas or vacation destinations with highly transient populations, meaning that the targeted district produced the highest offense rates of any residential metropolitan district. Among those crimes in which an offender could be identified, $35.8 \%$ of the known offenders were aboriginal. This percentage is obviously disproportionate with the aboriginal representation with the district $(2.3 \%)$, but is not entirely out of the ordinary for metropolitan Perth, with the district sitting at the $79^{\text {th }}$ percentile on this measure.

\section{2 | Unit of Analysis and Random Assignment}

We conducted the present experiment in 15 separate hot spot locations, each defined as a square 200-by-200 meters in size. The hot spots were first identified using a combination of recorded offenses and calls for service from the WAPF computer-aided dispatch (CAD) system. Initially, 41 separate hot spots in the area surrounding the participating police station were selected as having enough activity to be eligible for the experiment. This list was then trimmed to just 15 participating hot spots, in accordance with the following inclusion rules:

1. All four commuter rail stations in the local area had to be included,

2. No participating hot spot could share a border with another participating hot spot,

3. All locations had to be within $5 \mathrm{~km}$ of the participating police station, and,

4. Each location was approved by a committee which included the officer-in-charge of the participating station and the supervising sergeants of the local policing teams who would deliver the targeted hot spot patrols.

These 15 hot spot squares (mapped as Figure A.1 in the Appendix) were somewhat concentrated in the most heavily-populated portion of the police district, but were still comparatively spread out from one another. Among the 105 unique pairs of hot spot locations, only two were 
placed at the minimum possible distance (400 meters) from one another. Ninety $(85 \%)$ of the hot spot pairs were more than one kilometer apart. The average distance between the hot spot pairs was more than 2.5 kilometers, with a maximum distance of 5.2 kilometers. The likelihood of either spatial displacement or diffusion of benefits (Clarke \& Weisburd, 1994) occurring between the hot spot locations is therefore rather small.

The RCT was first conceived to test the introduction of bicycle patrolling into one of the six separate local policing teams. This single team was provided not only with bicycles to serve as their primary means of transportation, but also with specialized clothing and training in support of this new role. At the time, it was hypothesized that bicycle transportation would provide a number of benefits in delivering patrols to hot spots. As will be shown below, these hopes do not appear to have borne fruit, but they were nevertheless a key element of the experimental design.

The study ran for 248 days between August 2017 (mid-winter in the southern hemisphere) and April 2018 (mid-autumn), using the 15 selected hot spots in a series of daily random assignments. All 15 hot spots were reshuffled into a random order each day. Based on their randomly-selected order in this sequence, three or four of the hot spots were assigned to be patrolled by officers engaged in traditional automotive patrols. ${ }^{2}$ Because bicycle transport was used by only a single team of officers, this form of patrol could be delivered only on days when this team was working. On these days, the bicycle team was assigned to visit the next three locations in the randomly-sorted list of hot spots. When this team was not working, these locations were instead allocated to the control condition. The remaining locations, randomly selected anew each day, were also assigned to the control group.

This procedure therefore randomly allocated between three and seven hot spots to the treatment, "targeted patrol" condition each day. The supervising sergeants were asked to deliver at

\footnotetext{
${ }^{2}$ The experiment began on 21 August 2017, with 4 different automotive locations chosen each day. After a few months, it became apparent that the car teams were having trouble meeting the requirement to visit all four locations every single day. On 16 October 2017, the random assignment was changed so that only three locations were selected for automotive patrol, and this allocation continued until the end of the experiment on 25 April 2018.
} 
least two separate patrols, each lasting at least 20 minutes, to each of these treatment locations. This same number and duration of patrols was requested from both bicycle and automotive teams. In total, the treatment should have delivered at least 40 minutes per day of fairly-persistent police presence in each targeted hot spot. The remaining 8-12 of the locations, meanwhile, were allocated to the control condition for that day, with police presence to be provided in the usual manner. While the control condition did not preclude the use of targeted patrolling, no specific patrol count or duration was requested for these locations. Over the full 248 days of the experiment, 800 locationdays were randomly assigned to automotive patrol, 525 were assigned to bicycle patrol, and 2,395 were allocated to the control condition. All of our findings use these location-days as the unit of analysis and compare different randomly-assigned groups of them to one another, using an intentionto-treat (ITT) framework.

\section{3 | Treatment Content and Measurement}

Apart from the number and duration of their visits, the participating officers were given no instructions about how they should behave while conducting their targeted hot spot patrols. The officers were free to interact with the public, or to remain relatively unengaged while providing little more than a visible police presence. In part, this absence of instructions was intentional, in hope that the bicycle and automotive officers would naturally provide different forms of engagement that could lead to differing crime control outcomes. But even more importantly, we had no reliable means of measuring these activities by the officers, and it would have been impossible to monitor their compliance with any specific instructions regarding engagement with the community. In addition, we believed that simply monitoring the geographic location of the officers during these

patrols would be challenging enough, and that asking for specific behaviors during these visits could negatively affect the officers' willingness to deliver the patrols at all.

To measure the delivery of patrols during the experiment, the 46 local policing officers were provided with GPS-enabled smart phones, each of which was programmed to record the device's 
physical location every two seconds whenever the device was in physical motion. In actual practice, the phones did not always have the required visibility of GPS satellites to produce "pings" on this demanding schedule, but the tracking application installed on the phones recorded a wealth of information which allowed us to identify those pings that were sufficiently accurate to use for tracking and feedback purposes. In total, the phones used during this study produced 5.73 million separate location pings, with 5.17 million (90.3\%) meeting accuracy standards. ${ }^{3}$ For each valid ping, we calculated a duration value that extended halfway to the previous and subsequent valid ping from the same device. The result is each valid ping accounted for an average of 8.6 seconds of locational information.

The GPS data were used to produce daily and weekly feedback reports of patrol delivery to the treatment hot spots, and these reports were emailed to all participating officers and their supervisors. For the purposes of tracking and feedback, a buffer of an additional 20 meters was applied to the area surrounding each of the hot spots, so that patrol delivery was considered successful when officers were inside a 240-by-240 meter area. As mentioned earlier, the experimental goal was to deliver 2 separate patrols, each of 20 minutes in duration, to each of the treatment hot spot locations. To eliminate simple drive-through encounters, officers had to remain within the hot spots for at least 5 continuous minutes in order to be counted as a targeted patrol. To further eliminate long-term stays while handling specific calls for service, visits of longer than 30 minutes ${ }^{4}$ were also removed when defining the successful delivery of a patrol. Our operational definition of a "targeted hot spot patrol" is therefore an unbroken period of 5-30 minutes when at least one officer remained within 20 meters of a hot spot's boundary. Because WAPF officers nearly

\footnotetext{
${ }^{3}$ In order to qualify as valid for our purposes, a ping had to exhibit a positional accuracy value (in basic terms, the standard deviation of error between the phone's actual and measured locations) of 12.16 meters, meaning that it was $90 \%$ likely to be accurate within 20 meters, or $10 \%$ of each hot spot's width. A ping could also be deemed valid if it had a horizontal dilution of precision (HDOP) of 6.5 or lower, meaning that it fell into the "Good" or "Excellent" band in terms of horizontal (i.e., latitude and longitude, but not altitude) accuracy.

${ }^{4}$ For the purposes of the feedback reports that were provided to the participating officers, this limit was expanded to 40 minutes roughly halfway through the experiment, but for analysis purposes we have retained the original 5-30 minute definition of a targeted patrol.
} 
always work in pairs, most of these patrols represent the presence of at least two officers in the targeted hot spots.

\section{4 | Bicycle vs. Automobile Patrols}

Although the initial reasoning behind the experiment was to compare bicycles to automobiles, the bicycle team faced difficulty in consistently using their intended means of transportation. Deploying on bicycles required at least a pair of specially-trained officers, and the bicycle team did not always have enough of these officers available. This situation was less problematic in the five automotive teams, who could easily cross-team with one another while retaining their method of transportation. When bike-team officers switched to automotive travel, they were instructed to visit the automobile hot spots selected for that day instead of the bicycle hot spots that they would normally patrol. Based on their speed of travel as measured by their GPS devices, it seems that these bicycle-assigned officers clearly used cars regularly while working, and sometimes switched between bicycle and automobile multiple times during a single workday.

For the purposes of delivering targeted hot spot patrols, however, these complexities do not translate into any real difference in producing a visible police presence. The bicycle and automotive locations experienced almost identical levels of targeted patrol, with the same number (means of 0.63 vs. 0.70 patrols per day; $p=.251)$ and duration (11.06 vs. 11.09 minutes per day; $p=.976)$ of targeted police presence. Even more importantly, these two groups exhibited equivalent levels of both crime and police demand across all of our outcome measures. Bike and car locations reported similar amounts of offending, crime-harm (House \& Neyroud, 2018; Sherman et al., 2016), and calls for service, with no significant differences and only the smallest of effect sizes between the two randomly-assigned groups (see Table A.1 in the Appendix for a full comparison between bicycle and automotive groups). 


\section{5 | Treatment Delivery with Both Patrol Types Combined}

Based on this marked similarity between the bicycle and automobile location-days, the remainder of this paper ignores the transportation method assigned to each hot spot, combining the bicycle and automotive location-days together into a single treatment group $(n=1,325)$ that can be directly compared to the control group of location-days $(n=2,395)$ which were targeted for only business-as-usual patrolling. The elimination of the bike vs. car distinction also has some minor consequences for measuring patrol delivery, since it means that both transportation modes can be included when counting the number of successful 5-30 minute patrols provided to the treatment location-days, regardless of what patrol method that hot spot was assigned to receive. This form of transportation-agnostic accounting is essential here, because it mirrors the same counting rules that must apply when measuring patrol presence (in both forms) within the control group.

As can be seen in Table 1, there are enormous differences in patrol delivery between the combined bike-car treatment location-days and those assigned to the control group. Significant differences are observed in the likelihood, number, and duration of patrols. Table 1 also suggests that these differences in patrol delivery are concentrated primarily among those instances where the police remained on site for 5-30 minutes. Although we find significant treatment vs. control differences in overall patrol delivery when the duration of the visit is completely ignored, ${ }^{5}$ the effect sizes produced for patrolling generally are far smaller than those seen for the prescribed targeted patrols which lasted for the defined period of 5-30 minutes.

\footnotetext{
${ }^{5}$ Significant differences in patrol counts are also observed for those which lasted less than 2 minutes (3.95 patrols per location-day in treatment vs. 3.50 patrols in control; $p=.006$ ), those which lasted less than 5 minutes (4.26 patrols vs. 3.71 patrols; $p=.001)$, and those which lasted longer than 30 minutes $(0.09$ patrols vs. 0.02 patrols; $p<.001)$.
} 


\begin{tabular}{rrrr} 
Treatment & Control & $p^{\mathrm{a}}$ & Size $^{\mathrm{b}}$ \\
\hline
\end{tabular}

Sample size (location-days)

$1,325 \quad 2,395$

$\underline{\text { 5-30 Minute Patrols Delivered to Hot Spots }}$

\begin{tabular}{lrrrr} 
Proportion of location-days with at least one patrol & $46.1 \%$ & $16.7 \%$ & $<.001 *$ & 0.65 \\
Mean patrols delivered per location-day & 0.87 & 0.27 & $<.001 *$ & 0.56 \\
Mean minutes of patrol presence per location-day & 13.75 & 2.87 & $<.001 *$ & 0.71 \\
& & & & \\
& & & & \\
Any-Duration Patrols Delivered to Hot Spots & & & & \\
Proportion of location-days with at least one patrol & $81.9 \%$ & $72.2 \%$ & $<.001 *$ & 0.23 \\
Mean patrols delivered per location-day & 5.22 & 4.01 & $<.001 *$ & 0.22 \\
Mean minutes of patrol presence per location-day & 23.06 & 6.30 & $<.001 *$ & 0.39 \\
\hline
\end{tabular}

${ }^{\mathrm{a}}$ Two-tailed t-tests, assuming unequal variances

${ }^{\mathrm{b}}$ Cohen's $h$ for comparisons of proportions, Cohen's $d$ for all other comparisons

$* p<.05$

While these tests confirm that the experiment was successful in producing notable differences in police patrol across the two experimental groups, the dosage of patrolling under treatment conditions was far less than what was intended. This finding is consistent with a clear pattern of under-delivery in virtually all hot spots studies which have measured patrol time (Ariel, Weinborn \& Sherman 2016; Rosenfeld, Deckard, \& Blackburn 2014; Sherman \& Weisburd 1995; Williams \& Coupe 2017), but is nonetheless important in understanding the dosage-response effects in this experiment. On treatment days, a targeted 5-30 minute patrol was provided to the hot spots on less than half of the occasions. Although the experimental design called for 2 separate patrols per treatment-assigned day and at least 40 minutes of persisting police presence, the treatment locationdays instead received, on average, less than one such patrol and only 13.8 minutes of patrol delivery. Even when all police presence is combined, including "patrols" that lasted mere seconds, the treatment location-days accumulated a mean of only 23.1 minutes of daily police presence, amounting to just 58 percent of what the experimental design called for.

While this amount of patrol delivery may have been less than that specified by the experiment's design, it was uniformly higher than what was provided during the control location- 
days. One noteworthy feature of police patrol in this study was its remarkably low base rate, measured by how little of it was provided when the hot spots were placed into the control condition. A targeted patrol (i.e., 5-30 minutes in duration) occurred only once in every six control locationdays, and total police presence (of any duration) in the control group averaged just over six minutes per day. The result is that the effect sizes seen in Table 1, at least for targeted patrols, approach those that Cohen (2013) defines as "large". The experiment was therefore quite successful in producing a noteworthy increase in police presence to the hot spot locations on their treatment days. Moreover, these stark differences in patrol delivery continue even when the 15 separate hot spots are examined individually. Each of these separate locations experienced significantly more patrolling on treatment days when compared their control days (see Table A.2 in the Appendix for more detail). With strong confidence that the experiment produced a nearly five-fold difference between treatment and control days in targeted patrol delivery, we turn next to the question of whether these additional patrols had any effect on offending and the demand for police services.

\section{6 | Outcome Measures and Analytical Strategy}

The impacts of these patrols were measured using both officially-recorded criminal offending and computer-assisted dispatch data. The offending data were obtained from WAPF's Incident Management System (IMS), and include all reported criminal incidents which took place within the targeted police district during the 248 days of the randomised trial. In total, the data contain 5,836 incidents, which produced 8,727 separate offences. Although the 15 participating hot spots occupy just $0.008 \%$ of the land area within this police district, $464(8.0 \%)$ of these incidents and $640(7.3 \%)$ of these offences took place within their boundaries.

In addition to the standard prevalence and frequency measures that can be derived from the offending data, our analysis also takes advantage of the recently-developed Western Australia Crime-Harm Index (WACHI; House \& Neyroud, 2018) to measure the seriousness of each recorded offense. Similar to other harm indices (e.g., Curtis-Ham \& Walton, 2017; Ratcliffe, 2015; Sherman, 
Neyroud, \& Neyroud, 2016), the WACHI computes the amount of incarceration that a first-time offender typically experiences when sentenced for a particular offense by the Western Australian courts. All of the offences recorded within the hot spots were successfully matched with a harm value from the WACHI, revealing 168,296 incarceration-days of crime-harm (460.8 years) which took place across the entire district during the RCT. 15,598 of these incarceration-days $(9.3 \%)$ occurred within the participating hot spots.

The demand for police services was measured using data from the agency's computer-aided dispatch (CAD) system. All CAD jobs within the participating police district are available in these data, including those initiated by the public (usually through an emergency or non-emergency telephone number), as well as those jobs which were created on the system by the police themselves. The CAD data include measures of job type and location, how many of these jobs resulted in officers physically attending these locations, how many police units responded to each job, and the amount of officer time each job took to complete. A district-wide total of 18,426 CAD jobs took place during the study, with 1,266 (6.9\%) of these jobs occurring within the participating hot spots.

As is typical with randomized trials, the causal impact of patrolling can be easily estimated using standard $t$-tests (two tailed, and assuming unequal variances) when comparing the two groups (i.e., treatment and control) to one another. In other analyses, which examine these effects over multiple consecutive days of exposure to either the treatment or control condition, a one-way analysis of variance (ANOVA) is employed.

\section{4 | FINDINGS}

\section{1 | Initial Deterrence}

The experiment clearly demonstrated the initial deterrent effect of each treatment day relative to each control day. Given the existing literature and the strong differences in police presence, it is not surprising that these highly-elevated hot spot patrols caused a reduction in reported crime. As 
Table 2 demonstrates, all of the crime-related differences are in the expected direction, with less offending occurring when hot spots were assigned to the treatment condition. Although the difference in offending prevalence - defined here as the percentage of location-days in which at least one offense was recorded - is not statistically significant, the number (frequency) of offenses is significantly reduced when hot spots were assigned to received targeted patrols.

TABLE 2. Reported Offending and Response Demand; Treatment vs. Control

Effect

\begin{tabular}{lllll} 
Treatment & Control & $p^{\mathrm{a}}$ & Size $^{\mathrm{b}}$ \\
\hline
\end{tabular}

\begin{tabular}{lll}
\hline Sample size (location-days) & 1,325 & 2,395
\end{tabular}

$\underline{\text { Reported Criminal Offending }}$

$\begin{array}{lllll}\text { Prevalence of location-days with at least one offense } & 10.5 \% & 11.8 \% & .215 & -0.04\end{array}$

$\begin{array}{lllll}\text { Mean offenses reported per location-day } & 0.15 & 0.19 & .044^{*} & -0.07\end{array}$

$\begin{array}{llllll}\text { Mean crime-harm of offenses (outliers removed) } & \text { c } & 1.45 & 3.81 & .033^{*} & -0.07\end{array}$

Demand for Police Response

$\begin{array}{lllll}\text { Prevalence of location-days with requested tasking } & 24.8 \% & 23.1 \% & .244 & 0.04\end{array}$

Mean tasks requested per location-day

$\begin{array}{llll}0.35 & 0.33 & .308 & 0.03\end{array}$

$\begin{array}{lllll}\text { Prevalence of location-days with attended tasking } & 19.1 \% & 18.4 \% & .611 & 0.02\end{array}$

$\begin{array}{lrrrrr}\text { Mean tasks attended per location-day } & 0.25 & 0.24 & .683 & 0.01\end{array}$

\begin{tabular}{lllll} 
Mean minutes of tasking attended (outliers removed) $^{\mathrm{d}}$ & 14.14 & 13.63 & .797 & 0.01 \\
\hline
\end{tabular}

${ }^{\mathrm{a}}$ Two-tailed t-tests, assuming unequal variances

${ }^{\mathrm{b}}$ Cohen's $h$ for comparisons of proportions, Cohen's $d$ for all other comparisons

${ }^{c}$ Excludes any offenses where the crime-harm value exceeds three years (1,096 days) of incarceration

${ }^{\mathrm{d}}$ Excludes any dispatch tasking where the job was attended for more than 12 hours $* p<.05$

Table 2 also provides comparative measures of crime-harm, as measured using the Western Australia Crime Harm Index (WACHI) that was described above. As described by House and Neyroud (2018), the vast majority of offenses on this scale sit at the lower end of the range, with only a few days of crime-harm ascribed to them. A tiny number of more serious offenses, however, contribute much higher amounts of relative crime-harm. One particular difficulty in using crimeharm values are these very rare and exceedingly serious criminal events. These offenses carry outsized levels of crime-harm and act as strong outliers on the overall distribution. 
This issue is a particular concern for preventive patrol studies such as this one, since serious offenses also tend to be more complex and can extend wider than a single instant within a small geographic area. For the purposes of this study, our harm measures deal with such outliers by excluding any offenses where the crime harm exceeds three years (1,096 days) of potential incarceration. Although this exclusion affects only three incidents ${ }^{6}$ over the course of 248 days, their removal from the analysis is essential in revealing the systematic crime-harm differences between the two experimental groups. Excluding these outliers also allows us to focus on the events which occur most regularly in the experimental locations, which are driven primarily by lower-harm, streetlevel offending. Note that this exclusion affects only the comparisons of crime-harm, and that no offences were excluded from the measurement of either the prevalence or frequency of criminal acts.

As shown in Table 2, the targeted patrols produce a significant reduction in this adapted measure crime-harm. ${ }^{7}$ The size of this shift, however, bears special attention. Although the mean number of reported offenses declines by just 21.9 percent when hot spots were assigned to the treatment group, the amount of crime harm drops by nearly triple this amount (61.9 percent). This pattern suggests that the targeted patrolling not only prevented offending generally, but had an especially powerful impact upon more serious forms of criminal behavior with higher crime-harm values.

Although patrolling had clear impacts of offence count and crime harm, it had no effect whatsoever on the demand for police services. The prevalence and frequency of jobs placed on the CAD system, representing a request for police attendance, was no different between the treatment and control groups. These measures also exhibited no difference when the CAD data were limited to

\footnotetext{
${ }^{6}$ These three incidents involved four allegations of illegal sexual penetration, which carries a crime harm value of 1,140 days (3.12 years). Two of these incidents occurred within treatment location-days, while one took place under the control condition. In each case, the sequence of events began within the hot spot, but the most serious offending took place after the victim was taken to another location. Note that only these specific offences have been removed from the analysis, and that all other crimes associated with these incidents are retained in the data.

${ }^{7}$ When the outlier crime harm values are retained in the data, this difference is no longer significant, with means of 4.03 in the treatment group and 4.28 in control $(p=.911)$. The fact that just three incidents (four offences) can have such a dramatic effect on this testing lends increased confidence to our decision to exclude them.
} 
those where the police went on to physically attend the location, and there was no difference in how much time officers spent responding to these calls for service.

\section{2 | Random Assignment to Consecutive Days of Treatment or Control}

While the initial deterrent effects may not be surprising, the residual deterrence effects persisted far longer than expected. Yet even more remarkable was the trajectory of a sudden and massive collapse of those effects. We are able to see the evidence for these claims very clearly as a consequence of the experimental design, which re-shuffled the 15 hot spot locations anew each day. This design created random patterns of sequential assignment of the same hot spot to the same condition on successive days of the experiment. On each day of the study, every location had a somewhat-shifting probability of repeating the same randomly-assigned condition that it had been allocated to it during the previous day. These assignments then had a measurable likelihood of being repeated again on each of the subsequent days, and a continuous string would end only when the locations were randomly assigned to the alternate condition. The probabilities involved in random selection mean that the sample sizes in these strings grow smaller with each passing day. Because there were fewer daily assignments to the treatment group $(1,325)$ than there were to the control condition $(2,395)$, the duration of any continuous assignment strings tended to be shorter within the treatment condition. The longest consecutive period that any one location remained in the treatment group lasted just 9 days, as opposed to a maximum of 20 sequential days of continuous assignment to control. Table 3 provides detailed sample sizes on each day of consecutive random assignment to both treatment and control. 
TABLE 3. Available Sample Sizes on Successive Days of Sequential Assignment to the Same Condition

\begin{tabular}{|c|c|c|c|c|c|c|}
\hline & \multicolumn{3}{|c|}{ Treatment } & \multicolumn{3}{|c|}{ Control } \\
\hline & $n$ & Percent & $\begin{array}{r}\text { Cum. } \\
\text { Percent }\end{array}$ & $n$ & Percent & $\begin{array}{r}\text { Cum. } \\
\text { Percent }\end{array}$ \\
\hline 1st day & 833 & $62.9 \%$ & $62.9 \%$ & 835 & $34.9 \%$ & $34.9 \%$ \\
\hline 2nd day & 304 & $22.9 \%$ & $85.8 \%$ & 553 & $23.1 \%$ & $58.0 \%$ \\
\hline 3rd day & 112 & $8.5 \%$ & $94.3 \%$ & 355 & $14.8 \%$ & $72.8 \%$ \\
\hline 4th day & 44 & $3.3 \%$ & $97.6 \%$ & 235 & $9.8 \%$ & $82.6 \%$ \\
\hline 5th day & 17 & $1.3 \%$ & $98.9 \%$ & 149 & $6.2 \%$ & $88.8 \%$ \\
\hline 6th day & 8 & $0.6 \%$ & $99.5 \%$ & 90 & $3.8 \%$ & $92.6 \%$ \\
\hline 7th day & 5 & $0.4 \%$ & $99.9 \%$ & 61 & $2.6 \%$ & $95.1 \%$ \\
\hline 8th day & 1 & $0.1 \%$ & $99.9 \%$ & 47 & $2.0 \%$ & $97.1 \%$ \\
\hline 9th day & 1 & $0.1 \%$ & $100.0 \%$ & 27 & $1.1 \%$ & $98.2 \%$ \\
\hline 10th day & & & & 16 & $0.7 \%$ & $98.9 \%$ \\
\hline 11th day & & & & 10 & $0.4 \%$ & $99.3 \%$ \\
\hline 12 th day & & & & 5 & $0.2 \%$ & $99.5 \%$ \\
\hline 13th day & & & & 4 & $0.2 \%$ & $99.7 \%$ \\
\hline 14th day & & & & 2 & $0.1 \%$ & $99.8 \%$ \\
\hline 15th day & & & & 1 & $0.0 \%$ & $99.8 \%$ \\
\hline 16th day & & & & 1 & $0.0 \%$ & $99.8 \%$ \\
\hline 17 th day & & & & 1 & $0.0 \%$ & $99.9 \%$ \\
\hline 18th day & & & & 1 & $0.0 \%$ & $99.9 \%$ \\
\hline 19th day & & & & 1 & $0.0 \%$ & $100.0 \%$ \\
\hline 20th day & & & & 1 & $0.0 \%$ & $100.0 \%$ \\
\hline Totals & 1,325 & & & 2,395 & & \\
\hline
\end{tabular}

These random periods of consecutive assignment provide a unique opportunity. They allow us to see what happens when a location is repeatedly exposed to hot spot patrolling, and also what happens when targeted patrols are removed over a long sequence of days. Because these strings of sequential assignment occur at random within the data, each consecutive day of exposure to either treatment or control can be compared to those which occur earlier or later in the string, in the same manner that any two randomly-assigned events can be compared to one another to demonstrate a causal effect.

Of course, there are limits. Because the probability of repeating the previous day's assignment was always less than 1.0, the sample size eventually falls low enough that further analysis would become unfruitful. When this limit is reached, it makes more sense to collapse the 
later portion of these longer sequences into a single group. For this experiment, the sample sizes allow us to compare the first, second, and third days of sequential treatment-group assignment to one another, with the fourth and later days all collapsed into a single "fourth+" group of location-days ( $n$ $=76$, or just $2.5 \%$ of the treatment group). The control group, meanwhile, offers more opportunity for sequential analysis. The first through sixth days of consecutive assignment to control can each be examined individually, with a "seventh+" group ( $n=178$, or $7.4 \%$ of the control group) used to combine all days that occur later in these assignment strings.

\section{3 | Initial Deterrence Over Consecutive Days of Treatment}

Repeated exposure to the treatment condition does not appear to produce much of an impact, with one (perhaps humorous) exception. When officers were asked to patrol the same location on several consecutive days, patrol delivery remained unchanged for the first three days, at levels very consistent with the treatment group means shown in Table 1. After being asked to go to the same sites on four (or more) days in a row, however, these same officers suddenly exhibited a sharp increase in compliance with random assignment. As shown in Table 4, 60\% of the location days in the "fourth+" treatment group received a targeted patrol of 5-30 minutes in length, the mean number of these patrols grew to 1.39 , and the duration of police presence increased to 21.0 minutes. This sharp expansion of patrolling is statistically significant for all three of these measures. This pattern seems to suggest that the participating officers were responsive to being repeatedly pestered about patrolling the same location, and finally increased their compliance with random assignment after multiple consecutive daily requests. 
TABLE 4. Patrol Delivery, Reported Offending, and Response Demand; Consecutive Days of Random Assignment to the Treatment Group ${ }^{\mathrm{a}}$

\begin{tabular}{lrrrrr}
\hline & 1st day & 2nd day & 3rd day & 4th+ day & $p^{\text {b }}$ \\
\hline Sample size (location-days) & 833 & 304 & 112 & 76
\end{tabular}

\section{5-30 Minute Patrols Delivered to Hot Spots}

Prevalence of location-days with at least one patrol $46.7 \%$

Mean patrols delivered per location-day

\section{Reported Criminal Offending}

Prevalence of location-days with at least one offense

$\begin{array}{rrrrl}10.0 \% & 11.5 \% & 9.8 \% & 13.2 \% & .750 \\ 0.14 & 0.16 & 0.13 & 0.21 & .582 \\ 0.73 & 0.99 & 1.02 & 11.84 & .000^{*}\end{array}$

Mean offenses reported per location-day

0.73

\section{Demand for Police Response}

Prevalence of location-days with requested tasking

Mean tasks requested per location-day

$\begin{array}{rrrrl}25.0 \% & 23.0 \% & 25.0 \% & 28.9 \% & .747 \\ 0.37 & 0.29 & 0.33 & 0.38 & .388 \\ 19.0 \% & 18.8 \% & 21.4 \% & 18.4 \% & .930 \\ 0.26 & 0.23 & 0.26 & 0.24 & .895 \\ 11.98 & 14.99 & 16.17 & 31.35 & .038^{*}\end{array}$

Prevalence of location-days with attended tasking

Mean tasks attended per location-day

${ }^{a}$ These time periods cover 1-9 consecutive days of assignment to the treatment group following at least one day assigned to the control group

${ }^{\mathrm{b}}$ ANOVA $F$ test, $\mathrm{df}=(3 ; 1,321)$

${ }^{c}$ Excludes any offenses where the crime-harm value exceeds three years (1,096 days) of incarceration

${ }^{\mathrm{d}}$ Excludes any dispatch tasking where the job was attended for more than 12 hours

$* p<.05$

These increased patrols, however, are not associated with any obvious shifts in either

offending or police response. Instead, the prevalence and frequency of both recorded criminal

offenses and dispatch tasks stays consistent across all four consecutive day-groups in the treatment condition, with no significant differences found across them. ${ }^{8}$ These findings suggest that a single day of targeted patrol has roughly the same effect as returning to the same location for many days in

\footnotetext{
${ }^{8}$ The data do show a significant increase, in only the "fourth+" treatment group, for both crime-harm and the number of minutes spent attending to dispatch tasks. These differences can be tied to a single armed robbery which took place after six consecutive days of assignment to the treatment condition. While the neither the crime-harm value for this offense (760 days of incarceration) nor the minutes spent responding to it ( 7 separate police units responding to 2 different tasks, combining for 15 hours of response) are considered outliers, this single event does have a fairly outsized effect in the sample of just 76 location-days which experienced four or more consecutive days of treatment.
} 
a row, while also providing confidence that all of the treatment location-days can be treated as a single randomly-assigned group for analysis purposes.

\section{4 | The "Sweet Spot" of Residual Deterrence and its Sudden Disappearance}

The same cannot be said for repeated daily exposure to the control condition, in which we observed persisting residual deterrence effects for four days until a sharply defined collapse on the fifth day. The overall pattern is depicted in detail in Figure 1, which plots four different measures of offending and demand across multiple days of recurring assignment to the control group. The $F$ tests shown on the figure stem from one-way analyses of variance (ANOVAs), which compare each of the seven sequential day categories ${ }^{9}$ to one another. Although a statistically significant difference was identified only for response tasking (which stands in sharp contrast to the absence of any treatment vs. control differences shown in Table 2), all four measures show a similar and intriguing pattern. For the first four consecutive days after the most recent targeted patrolling (shown in light blue), crime and demand stay relatively low. Indeed, demand drops below the value that was observed on treatment days, which is shown as a dotted line on each graph.

Beginning on the fifth day, however, both crime and demand begin to increase, and this pattern is maintained (with suggestions of steadily increasing counts) on each of the subsequent days of business-as-usual patrolling (shown in dark blue). At least in these Western Australia hot spots, the benefits of (notably modest) targeted patrolling are remarkably persistent. A small amount of police presence, amounting to roughly a single visit of nearly fourteen minutes, continues to influence behavior for several days afterwards - many times longer than the patrol time it took to generate it - without any requirement to return to the same location. Instead of needing to continually refresh the deterrent effect with further heightened patrolling, the police could instead

\footnotetext{
${ }^{9}$ The results shown in Figure 1 do not depend on our decision to collapse the later control day categories into a single "seventh+" group. Alternate analyses, using either a "sixth+" or an "eighth+" truncation strategy, returned nearly identical findings to the $F$ tests shown in Figure 1.
} 
maintain it with nothing more than minimal, business-as-usual visits to these hot spots, with many patrols lasting just a few seconds.
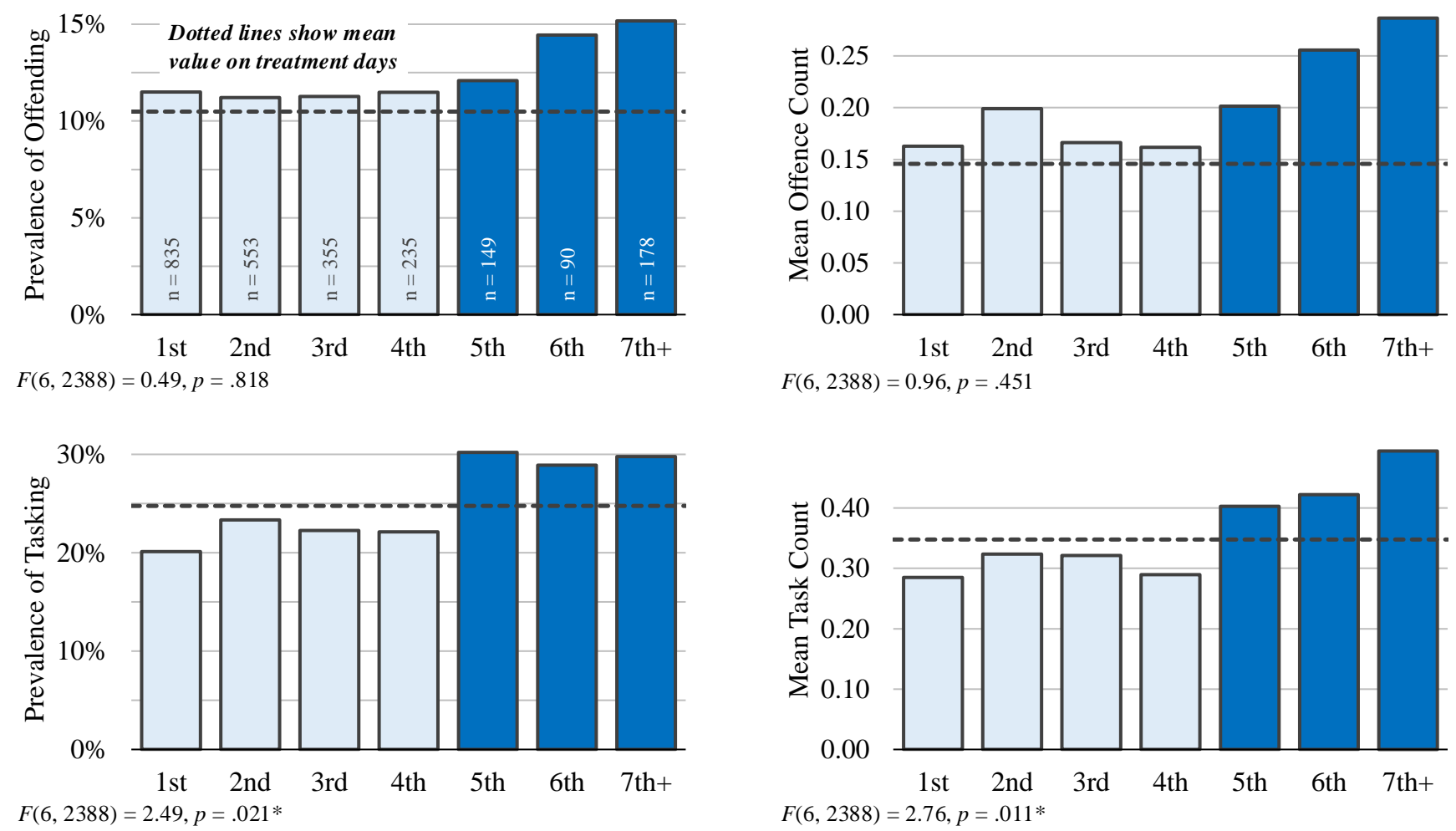

FIGURE 1. Offending and Demand over Successive Days of Sequential Assignment to Control Condition

Figure 1 also suggests that this residual deterrent effect ends with a speed that is more of a sharp and sudden "collapse" than the slow and gradual "decay" suggested by Sherman (1990). Crime and demand for police response both seem remarkably consistent during the first four days of assignment to the control group, but jump sharply upward once a location reaches five days without any targeted patrolling. Based on this pattern, it should be possible to gain a bit of statistical power which is strongly limited by some of the small daily sample sizes presented in Table 3 - by combining the full sample of location-days into just three groups: treatment days, initial control days (1-4 days of consecutive assignment to no patrol), and extended control days (5+ days with no patrol). The results of this analysis are provided in Table 5. 
TABLE 5. Patrol Delivery, Reported Offending, and Response Demand; Treatment, 1-4 Days of Control, and 5+ Days of Control

\begin{tabular}{|c|c|c|c|c|c|c|c|c|c|c|}
\hline & \multicolumn{4}{|c|}{ Comparisons Across All Three Groups } & \multicolumn{2}{|c|}{$\begin{array}{c}\text { Initial } \\
\text { v. Treatment }\end{array}$} & \multicolumn{2}{|c|}{$\begin{array}{c}\text { Extended } \\
\text { v. Treatment }\end{array}$} & \multicolumn{2}{|c|}{$\begin{array}{c}\text { Extended } \\
\text { v. Initial }\end{array}$} \\
\hline & \multirow[b]{2}{*}{ Treatment } & \multirow{2}{*}{$\begin{array}{r}\text { Initial } \\
\text { Control }^{\mathrm{a}}\end{array}$} & \multicolumn{2}{|c|}{ Extended } & \multicolumn{2}{|c|}{ Effect } & \multirow{2}{*}{\multicolumn{2}{|c|}{$\begin{array}{ll} & \text { Effect } \\
p^{\mathrm{d}} & \text { Size }^{\mathrm{e}}\end{array}$}} & \multirow[b]{2}{*}{$p^{\mathrm{d}}$} & Effect \\
\hline & & & Control $^{\mathrm{b}}$ & $p^{\mathrm{c}}$ & $p^{\mathrm{d}}$ & Size $^{\mathrm{e}}$ & & & & Size ${ }^{\mathrm{e}}$ \\
\hline Sample size (location-days) & 1,325 & 1,978 & 417 & & & & & & & \\
\hline \multicolumn{11}{|l|}{ 5-30 Minute Patrols Delivered to Hot Spots } \\
\hline Proportion of location-days with at least one patrol & $46.1 \%$ & $16.6 \%$ & $17.5 \%$ & $<.001 *$ & $<.001 *$ & -0.65 & $<.001 *$ & -0.63 & .745 & 0.02 \\
\hline Mean patrols delivered per location-day & 0.87 & 0.28 & 0.25 & $<.001 *$ & $<.001 *$ & -0.55 & $<.001 *$ & -0.61 & 692 & -0.04 \\
\hline Mean minutes of patrol presence per location-day & 13.75 & 2.93 & 2.56 & $<.001 *$ & $<.001 *$ & -0.70 & $<.001 *$ & -0.75 & 696 & -0.04 \\
\hline \multicolumn{11}{|l|}{$\underline{\text { Reported Criminal Offending }}$} \\
\hline Proportion of location-days with at least one offence & $10.5 \%$ & $11.4 \%$ & $13.9 \%$ & .158 & .529 & 0.03 & .124 & 0.10 & .235 & 0.08 \\
\hline Mean offences reported per location-day & 0.15 & 0.17 & 0.25 & $.020 *$ & .331 & 0.05 & $.046^{*}$ & 0.12 & .087 & 0.08 \\
\hline Mean crime-harm of offences (outliers removed) ${ }^{\mathrm{f}}$ & 1.45 & 3.10 & 7.18 & $.032 *$ & .342 & 0.05 & $.032 *$ & 0.11 & .120 & 0.06 \\
\hline \multicolumn{11}{|l|}{ Demand for Police Response } \\
\hline Proportion of location-days with requested tasking & $24.8 \%$ & $21.6 \%$ & $29.7 \%$ & $.001 *$ & .098 & -0.07 & .094 & 0.11 & $.005^{*}$ & 0.19 \\
\hline Mean tasks requested per location-day & 0.35 & 0.30 & 0.45 & $.001 *$ & .145 & -0.07 & $.050^{*}$ & 0.12 & $.003^{*}$ & 0.18 \\
\hline Proportion of location-days with attended tasking & $19.1 \%$ & $17.3 \%$ & $23.7 \%$ & $.008^{*}$ & .296 & -0.05 & .089 & 0.11 & $.014^{*}$ & 0.16 \\
\hline Mean tasks attended per location-day & 0.25 & 0.22 & 0.34 & $.002 *$ & .292 & -0.05 & $.044 *$ & 0.12 & $.005^{*}$ & 0.17 \\
\hline Mean minutes of tasking attended (outliers removed) ${ }^{\mathrm{g}}$ & 14.14 & 13.00 & 16.63 & .485 & 656 & -0.02 & .535 & 0.04 & .347 & 0.06 \\
\hline
\end{tabular}

${ }^{\mathrm{a}}$ This period covers the first four consecutive days of assignment to the control group following at least one day assigned to the treatment group

${ }^{\mathrm{b}}$ This period covers five or more consecutive days of assignment to the control group following at least one day assigned to the treatment group

${ }^{\mathrm{c}}$ ANOVA $F$ test, $\mathrm{df}=(2 ; 3,717)$

${ }^{\mathrm{d}}$ Reports the maximum value for $p$ from the Tukey-Kramer studentized range test (HSD), the Bonferroni $t$ test of differences between means, and Scheffe's multiple comparison procedure

${ }^{\text {e}}$ Cohen's $h$ for comparisons of proportions, Cohen's $d$ for all other comparisons

${ }^{\mathrm{f}}$ Excludes any offences where the crime-harm value exceeds three years (1,096 days) of incarceration

${ }^{\mathrm{g}}$ Excludes any dispatch tasking where the job was attended for more than 12 hours

$* p<.05$ 
Three important patterns are revealed by this approach. First, the delivery of targeted patrols was unambiguously higher during the treatment days when compared to either of the two control groups. Even more importantly, patrolling was quite consistently low across the full range the control location-days. There are no observable differences between the amount of patrol delivered during the initial control period and that provided when the control condition continued for an extended time. Whatever differences might exist between the initial and extended periods of control, those changes clearly cannot have resulted from any differences in police presence. ${ }^{10}$

Secondly, the significant reductions in offending previously observed earlier in Table 2 are driven almost entirely by what transpired within the extended control location-days. There are no significant differences in offending between treatment days and initial control days, and the effect sizes from these comparisons are miniscule. This finding tells us that offending during these first four days of control mirrored what transpired on (treatment) days of targeted hot spot patrolling. The police essentially got these four days of crime reduction for free. They didn't need to patrol during these control days, but offending behaved as if the targeted patrols were still active and present within the hot spots.

The extended control group, meanwhile, provides a remarkable contrast with the treatment condition, particularly in terms of crime-harm. While crime levels may have been consistent prior to this point, hot spots that went five or more days without targeted patrolling saw explosive increases in offending as a result. Admittedly, the effect sizes seen here fall into a range that Cohen (2013) would identify as less than "small". But the magnitude of the observed difference in crime-harm represents nearly a five-fold increase between what happened on treatment days, and what took place just five days later. These findings suggest that a long-term absence of targeted patrol not only increases the number of crimes that occur within hot spots, but also strongly changes the nature of this offending in ways that make it far more serious and harmful.

\footnotetext{
${ }^{10}$ The same pattern exists when all patrols of any duration (including those resulting from only momentarily passing through the hot spot) are included in this measure. Although the differences between the treatment group and both control groups shrink somewhat, there is no difference at all between the initial and extended groups.
} 
Thirdly, the demand for police response follows a somewhat unexpected pattern over time. Although Table 2 indicates that the (overall) difference between treatment and control (generally) is not significant when it comes to dispatch tasking, these global findings may be masking a much more nuanced trend. The first four consecutive days of the control condition produced a small (and non-significant) decline in demand when compared to the treatment group. At least during this initial control period, not providing patrols to the hot spots generated fewer response tasks than delivering a targeted police presence. Once the extended control period begins, however, the data reflect a noteworthy rise in demand. The most striking significant differences are not, as we might expect, between treatment and extended control (although a few tests manage to dip just under the significance threshold). Instead, the most consistent differences are between the initial and extended control groups. Targeted patrolling, in other words, has its biggest effect on response demand not while the police are delivering it, but after it comes to an end. The optimal way to reduce response tasking is by providing brief periods of intensified patrolling, and then waiting four full days before returning to the same location again.

The effect sizes and means shown in these analyses are somewhat small, but it is important to remember that the unit of analysis used here is a single location-day. The experiment employed 15 separate hot spots over 248 days, and it is worth considering what the results shown in Table 5 might mean if these three different conditions were applied to all of these locations over an entire calendar year. This presentation is necessarily speculative, as the effects observed in our findings would undoubtedly change if they were applied universally over such a long period. But they also illustrate the potential cost-effectiveness of such a strategy. Figure 2 is essentially a graphical representation of the same results already shown in Table 5, but multiplied in a way that reflects the true potential of these patterns within just this one station district of metropolitan Perth. The difference between extended control and treatment amounts to the prevention of 568 offenses per year $(41.6 \%$ reduction), and 31,424 incarceration-days (86.0 years) of crime-harm (79.8\% reduction). The difference between the initial and extended control periods, meanwhile, represents the elimination of 
537.6 dispatch tasks every year $(22.0 \%$ reduction). This decrease in calls for service could easily free up enough time to deliver the modest amount of targeted patrolling deployed during this experiment. The intervention could therefore be said to pay for itself, while greatly reducing the amount of crime and harm experienced by the community.
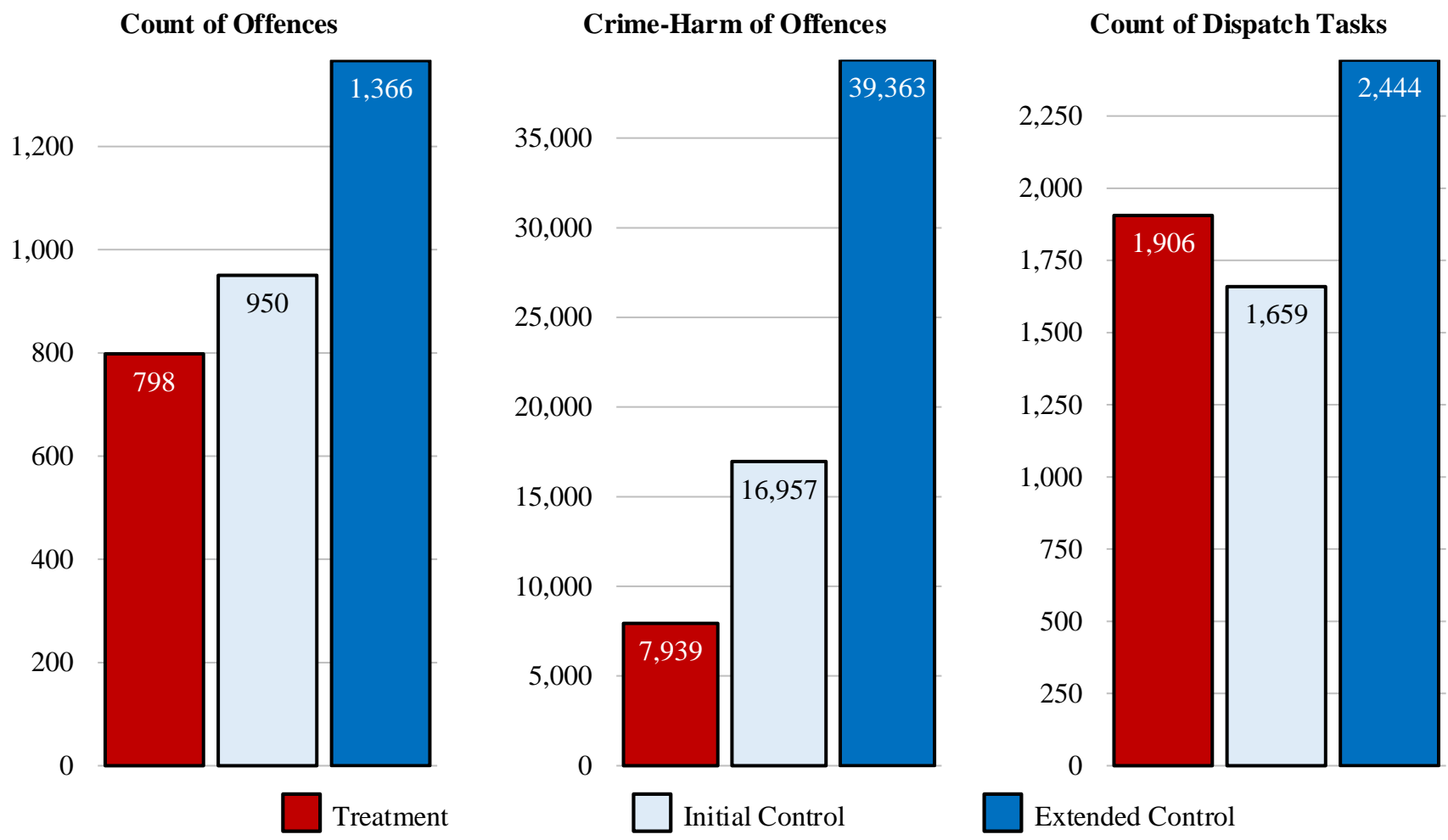

FIGURE 2. Annualised Offences, Crime-Harm, and Dispatch Tasks Across All 15 Hot Spots

\section{5 | DISCUSSION}

This research produced unexpected results. There is little prior evidence to support an expectation that a such a modest amount of targeted police patrolling - amounting, on average, to a single patrol visit per day lasting just under 14 minutes - should generate any reduction in either offending or the demand for police response. The crackdowns and decay patterns put forward by Sherman (1990), and explored further by others, were clearly not proposed with such tiny amounts of policing in mind. That this "minimalist" level of patrolling should continue to have a residual deterrence impact for four consecutive days afterwards is almost astonishing. Nevertheless, the methods used here clearly support a causal interpretation of these findings. These patrols produced a 
residual impact that lasted for several days, while also causing a noteworthy spike in crime and demand when the hot spots were left unpatrolled for longer periods of time.

These results from minimal patrol stand in stark contrast to parallel track experiments lasting for much longer periods of time, usually extending over many months. In the initial Minneapolis hot spots patrol experiment (Sherman \& Weisburd, 1995), for example, each of the 55 treatment hot spots was designed to have an entire year of extra patrol, every day, for 365 days. Most other experiments reviewed by Braga et al. (2014) provided at least 90 consecutive days of treatment.

Our findings, however, suggest that within the context of our test, longer-term continuous exposure to targeted patrolling may be both unnecessary and inefficient. There were no additive benefits to delivering patrols to the same places for multiple days in a row (see Table 4); offending remained the same, regardless of how many consecutive days the location received targeted patrols. If that is true for other communities in which hot spots experiments have been conducted, there may be a much stronger case for minimal patrol than prior evidence suggests.

These findings also highlight the importance of moving beyond simply counting offenses, and taking the seriousness of offending into account when measuring the impact of crime control efforts. The targeted patrols tested here, when compared to the control group generally, were successful in reducing the overall count of criminal acts by 22 percent, but had an even more noteworthy impact in lowering crime-harm by 62 percent (Table 2). Preventing crime is clearly important, but targeted patrolling had a particularly acute impact on the more serious offences which not only produce higher harm to the community, but are also more costly and time-consuming for the police to deal with. Were it not for the development of a local crime-harm index (House \& Neyroud, 2018), we could have easily missed this important distinction.

Another necessary feature of this research (as in Ariel et al., 2016; Williams \& Coupe, 2017) was the detailed tracking of patrol delivery through the collection of millions of GPS-recorded locations over the course of the experiment. Indeed, these results would likely have proven impossible to produce without these efforts. The GPS tracking data were certainly useful in 
measuring how much targeted patrol was delivered to each of the hot spot locations, but they were far more important in providing next-day feedback to the officers who were tasked with performing these patrols. The officers and their supervisors became acutely aware that their locations were being recorded, and that their targeted patrols within the hot spots needed to match the agreed-upon criteria in order to be successfully counted on the daily feedback reports. Without this effort, the compliance with random assignment would have been even lower than the somewhat-disappointing levels seen here. Any replication of our research will require similar tracking of patrol delivery and immediate feedback to the participating officers.

Finally, neither displacement nor diffusion of benefits seem likely to play much (if any) role in producing these findings. Spatially, all of the hot spots were located at least 400 meters from their closest counterpart, and even this distance was applied sparingly. Moreover, because the hot spots were randomly assigned anew each day, two nearby locations would often be assigned to the same condition simultaneously, so any displacement patterns would be complicated by both random assignment and police compliance with patrol delivery. These patterns should take place randomly across the thousands of location-days in the sample, and are therefore unable to exert any consistent impact on the results. Finally, an internal police analysis conducted shortly after the experiment concluded failed to find any significant indicators of displacement into the grid squares that immediately surrounded each of the 15 hot spots.

Other forms of displacement, however, such as a change to alternate offending types or to different periods of time (Barnes, 1995), are much more likely to have taken place. But far from weakening the impact of targeted patrolling, these forms of displacement could be seen as beneficial goals for such a strategy. A shift to less serious forms of offending, and delaying the return of more harmful crimes for several days - both of which seem to have occurred here - seems like quite a successful result when compared to what transpired when hot spot locations went unpatrolled for long periods of time. 


\section{1 | Limitations}

The primary limitation to this experiment, at least from the standpoint of deterrence theory, is the absence of any direct measures for the perceptions of or communications between potential offenders. While the cause and effect relations are not in doubt, the causal pathways that produced them remain inside an unseen "black box" (Haberman, 2016). There now seems to be good reason for future studies of this kind to look for causal mechanisms. One example would be to attempt to interview informants - and perhaps even arrestees - about their risk perceptions before, during and after the changes in police patrolling. Such qualitative work could be informed by theoretical perspectives on how potential offenders may, alone or in communication with each other, engage in “risk updating” (Anwar \& Loughran, 2011; Matsueda et al., 2006) based on recent observations of police actions or presence. Risk updating is the process of offenders absorbing new information about sanction certainty, which either increases or reduces the level of certainty of sanctioning that they perceive. Such concepts may provide a means of identifying a micro-mediation (Cook et al., 1979) of the causal links between police patrol and crime.

From the standpoint of policing policy, on the other hand, our primary limitation was in our inability to deliver the levels of patrol time that were called for by the design. While future publications may explore some quasi-experimental lessons learned in the process of trying to improve patrol delivery, in the short run we were saved by the unexpectedly large effects produced from such small amounts of patrol. Our study joins a long list of hot spot experiments where the delivery of targeted patrolling proved to be a challenge (Ariel et al 2016; Rosenfeld, Deckard, and Blackburn 2014; Sherman \& Weisburd, 1995; Taylor, Koper, \& Woods, 2011; Telep et al., 2014; Weisburd \& Green, 1995; Williams \& Coupe, 2017). The key difference here may have been the extremely low amounts of business-as-usual patrolling that took place during control days. It may be that targeted patrolling is especially powerful when the alternative is so comparatively weak. As Ariel and colleagues (2020) reported, the lower the baseline levels of patrol in the control condition, 
the more deterrent effect may be gained by still small, but proportionately much larger, doses of directed patrol time.

One nuance of this limitation was the frequent failure of our participating officers to remain in the treatment hot spots for any length of time. In a majority of instances (53.9\%), the treatment location-days experienced precisely zero of the 5-30 minute visits that defined a successful "targeted patrol". Instead of experiencing 40 minutes of such patrolling per day, these hot spots were exposed to an average of just 13.8 minutes, representing just 34.4 percent of the intended dosage. The issue was not so much whether the participating officers went to these locations, but how long they lingered once they arrived. More than $70 \%$ of the location-days in both groups (including control) experienced some brief patrols that lasted five minutes or less, with an average of nearly four such visits every day. Longer stays, however, were much harder to attain, which mirrors the findings of a separate study which tracked the movement of patrol officers within the Perth central business district (Oatley et al., 2019).

It may be that a replication of this work in other jurisdictions, where targeted, longer-duration patrols are more common, will produce different findings. We can only speculate on what our observed patterns of decay and residual deterrence might have been if the patrols had matched our initial intentions. Yet in a way, our discovery of the large returns from as little as 13.8 minutes of targeted patrol was serendipitous. Had we delivered as much patrol as we had thought necessary, we would not have learned how little was needed.

It is also important to recognize that these results are based on an intention-to-treat approach that inherently incorporates these limitations of treatment delivery into the analysis. On average, this approach is defensible, given the strong differences (in the aggregate) in patrolling between treatment and control days. Nevertheless, there were clearly wide swings in police presence across individual hot spots and location-days within the treatment group. Subsequent analyses of these data should explore whether higher levels of (actual) patrol delivery are associated with even lower 
amounts of offending during those treatment days, along with stronger residual effects once these locations reverted back to the control condition.

Many of these intention-to-treat findings feature small effect sizes, meaning that our significant findings are often dependent on the rather large sample sizes produced by our crossover design. Without several thousand location-days in the data, it is likely that these differences would have failed to achieve statistical significance. These lower effect sizes also mean that outlying values can be a key determinant in whether significance is attained. The crime-harm differences seen in Table 2, for example, are strongly influenced by our decision to remove the highest harm offences (all four of them) from analysis presented above. While we believe our decisions to be justified in light of the findings revealed through the exclusion of these offences, this step may not have been needed had the treatment effects been more robust than they were.

The data collected for this experiment are also lacking some important details. While GPS tracking allowed very precise measurement of where the participating officers were located, we were unable record what activities they were engaged in. No observational or self-report data were collected to measure what the officers did during their hot spot patrols. We can be certain that they were positioned within sight of the hot spot locations, and that they provided a visible police presence whilst they were there, but no further detail of their behavior is available for analysis.

The crime-harm metric used here poses a similar challenge in interpreting these results. Because hot spot patrolling (both initially and residually) reduced aggregate crime-harm much more than it reduced crime count, we can tell that targeted police presence had a stronger effect on more serious offending than it had on more ordinary, lower-harm crimes. But our data, especially when separated into treatment and control groups, are unable to support any detailed analysis of individual crime types. There simply are not enough instances of specific forms of offending taking place to provide a reliable estimate, for example, of whether visible patrols had a particularly strong impact on burglary or stealing from motor vehicles. Future replications of this work may need to expand the 
number of hot spots, or perhaps run for a longer period of time, to permit this kind of detailed analysis.

Another concern with the present study is the limited proportion of location-days that were randomly assigned to the treatment group when compared to the control group. Our study was able to examine residual deterrence because long sequences of control assignment (up to 20 days) were available in the data, providing usable sample sizes out to six consecutive days. The same was not true in the treatment group, which limited our ability to measure the impact of repeated exposure to targeted patrolling. While our findings suggest there is no accumulating advantage in patrolling for multiple consecutive days, this pattern may be an artifact of our limited time horizon for sequential exposure to the treatment condition. Future studies may want to adjust their random allocations to allow for a deeper and longer-lasting examination of these sequences.

Our data on the demand for police services present a few further limitations. More than $80 \%$ of the dispatch tasks in this analysis appear to come from members of the public, and were initiated over the telephone. The source for the remaining jobs, however, is deeply unclear, with the majority of these observations featuring missing data on how they were initiated. It is therefore impossible to distinguish between those tasks generated by external public demand, and those that were internally created by police officers. The demand patterns seen on treatment and (initial) control days contain some hints that police presence, in itself, is responsible for an increase in dispatch tasking. Without good information on the source of these jobs, however, we simply cannot say how much of this boost in demand is self-generated by the officers who were delivering the targeted patrols.

While these concerns are certainly notable, they can be addressed in future replications of our methods using repeated crossover designs. The limitations are important, but they do little to harm the internal validity of these findings. Whatever problems we faced in the amount of treatment delivery, the experiment was successful in producing strong levels of treatment integrity, in which the treatment days experienced far more police presence than the control days. The design allowed us to compare randomly-assigned sequences of continuous assignment to the same conditions, and 
explore the cumulative effects produced by providing multiple days of sequential treatment (or its absence) to single locations. This same method of random assignment allows us to infer causation to our observed outcomes, with confidence that these initial and extended residual effects were directly produced by the targeted patrols.

\section{6 | CONCLUSION}

The evidence in this article provides a clear answer to the operational research question, at least within the context of an Australian suburb known for relatively high rates of crime. That question is how much residual deterrence can be achieved from very minimalist levels of directed police patrols? That is not the question we started with, but the answer to it is the most important discovery of this experiment. The answer to that question is four days, after which we see a sharp spike in crime harm that is almost four times higher than that seen during periods of targeted patrolling. That answer is far longer and sharper than most police scholars and leaders may have expected. It also contradicts the trajectory of gradual decay that Sherman (1990) described on the basis of the quasi-experimental evidence available at the time. As the first research which has randomly assigned lengths of a patrol "drought," our experimental design has identified a potential for deterrent effects to be caused by minimalist patrols, and for the residual effects to last for several consecutive days afterward.

Despite the apparent logic of a "gradual" change in perceptions of risk, our empirical evidence requires a different logic of causation. It is beyond the scope of the present research to identify what that casual mechanism may be, or how (and if) it is communicated through social networks of potential offenders. However it may be produced, the four-day "sweet spot" pattern of residual deterrence seems consistently-timed in relation to fairly short doses of police presence. The implications of this fact for theory, research, and policy are all substantial.

The implication of these findings for deterrence theory is that spatio-temporal differences in perceived risk of sanctions may be far more variable and causally powerful than previously thought. 
Previous perception research in criminology has drawn heavily on measures of differences across people, rather than differences across areas or within areas over time. In order to unpack the many causal dynamics of deterrence, we will need to contextualize surveys - or even ethnographies - in terms of local differences in police and courts, as well as the effects of short-term changes.

The implication of these findings for research are equally fundamental: that future experiments in hot spots policing need to develop a barometer of offender risk perceptions in each hot spot policing area. Such a barometer could be based on daily interview measures of perceived risk of police sanctions (such as arrest). Wikström et al. (2012) have done exactly that in Peterborough (UK), where Ariel et al. (2016) conducted a randomized trial of foot patrols in hot spots. It should not, in principle, be too difficult to build mixed-methods research teams that can integrate daily self-reporting interviews with known local offenders, combining them with GPSmeasured dosage differences of police presence in different hot spots.

Whether or not research measures perceptions, the more basic issue is whether parallel-track experiments in patrol should be set aside for a new generation of repeat-crossover designs. This possibility was always a good theoretical response to the "real gold standard" critique by Nagin \& Sampson (2019). With these findings in hand, there is now empirical evidence to suggest that each small world can create its own counterfactual. In a sense, it suggests that what happens in each small world stays in each small world, without necessarily creating or depending upon a system-wide equilibrium. Whether that interpretation is valid may then depend on further empirical results from crossover designs. Such replications seem to be far more feasible than random assignment of entire cities to either use or not use prescribed hot spots patrolling strategies.

The implication of these findings for police policy are both digital and managerial. They are digital insofar as the tracking of consecutive minutes of police presence in hot spots is easily accomplished by GPS-enabled tracking and computers, and can become fully automated. Once the automation is available, there is an opportunity to have a program generate an "alarm" report for 
every time a crime hot spot has gone more than four days without an extended period of stationary patrol, lasting at least 14 minutes (if not more).

Once the alarm is generated digitally, the managerial implication becomes relevant. Some method must be available to process these hot spots alarms with the alacrity of a pilot hearing a cockpit alert, rather than with the glacial pace by which bench warrants for arrest are served on absconders from court appearance. The potential for finding the hot spots, fortunately, is far greater than the potential for finding each absconder. Yet the capacity for unheeded alarms to become a cultural pattern should not be underestimated; it was just such a pattern that led to 228 deaths on Air France Flight 447, where highly-trained pilots ignored audible stall warnings for several minutes until the aircraft fell into the sea (Salmon et al., 2016). The cultural value of an alarm in policing, however, should fit closely with the sense of obligation to "respond" to locations when assigned. Even if experiments are needed to learn how best to ensure a new "refresher" patrol after five or more days with no targeted patrolling, the managerial challenge must somehow be met to optimize those deterrent effects of uniformed police patrol.

These implications may all depend upon replicating the present experiment in other settings. Such replications would be enormously helpful, even without addressing the implications outlined above. The good news for such replications is that the level of patrol frequency needed for effective hot spots policing may be far smaller than previously thought. Moreover, the experiments can be conducted with a relatively small team of dedicated police pracademic researchers on patrol, much like the team deployed for the Birmingham experiment (Williams \& Coupe, 2017).

At the same time, the residual deterrence benefits of the 15-minute patrol visit identified by the Koper (1995) curve may be far longer than his data allowed him to measure, or than anyone had ever anticipated. If these findings are replicated, then the residual deterrence benefits of a fourteenminute police patrol may be 192 times longer than previously thought, simply because this study had the capacity to increase the measurement period for residual effects up to 20 days, or six days with adequate sample size. 
In a similar way, the growth of digital possibilities for measuring the constructs of deterrence theory have been more rapid than criminologists may have realized. We may be approaching the time when criminology can create a non-linear spike in the growth of our knowledge of general deterrence. Perhaps proving the benefits from repeated "booster patrols" by unexpected police arrivals can lead to a sudden collapse of skepticism about using research in policing - or even about the value of policing itself. 


\section{REFERENCES}

Anwar, S., \& Loughran, T. A. (2011). Testing a Bayesian Learning Theory of Deterrence among Serious Juvenile Offenders: Bayesian Learning and Deterrence. Criminology, 49(3), 667698. https://doi.org/10.1111/j.1745-9125.2011.00233.x

Ariel, B., Sherman, L. W., \& Newton, M. (2020). Testing Hot-Spots Police Patrols Against NoTreatment Controls: Temporal and Spatial Deterrence Effects in the London Underground Experiment. Criminology, 58(1), 101-128.

Ariel, B., Weinborn, C., \& Sherman, L. W. (2016). "Soft" Policing at Hot Spots-Do Police Community Support Officers Work? A Randomized Controlled Trial. Journal of Experimental Criminology, 12(3), 277-317. https://doi.org/10.1007/s11292-016-9260-4

Barnes, G. C. (1995). Defining And Optimising Displacement. In Crime Prevention Studies (Vol. 2, p. 19).

Berk, R. A., Campbell, A., Klap, R., \& Western, B. (1992). The Deterrent Effect of Arrest in Incidents of Domestic Violence: A Bayesian Analysis of Four Field Experiments. American Sociological Review, 57(5), 698. https://doi.org/10.2307/2095923

Bower, C., Watkins, R. E., Mutch, R. C., Marriott, R., Freeman, J., Kippin, N. R., Safe, B., Pestell, C., Cheung, C. S. C., Shield, H., Tarratt, L., Springall, A., Taylor, J., Walker, N., Argiro, E., Leitão, S., Hamilton, S., Condon, C., Passmore, H. M., \& Giglia, R. (2018). Fetal alcohol spectrum disorder and youth justice: A prevalence study among young people sentenced to detention in Western Australia. BMJ Open, 8(2), e019605. https://doi.org/10.1136/bmjopen2017-019605

Boydstun, J. E. (1975). San Diego Field Interrogation: Final Report. Police Foundation.

Braga, A. A., Papachristos, A. V., \& Hureau, D. M. (2012). Hot Spots Policing Effects on Crime. Campbell Systematic Reviews, 8(8), 1-96. 
Braga, A. A., Papachristos, A. V., \& Hureau, D. M. (2014). The Effects of Hot Spots Policing on Crime: An Updated Systematic Review and Meta-Analysis. Justice Quarterly, 31(4), 633663.

Brody, H. (1981). Physics of the Tennis Racket II: The 'Sweet Spot' . American Journal of Physics, 49(9), 816-819.

Clarke, R. V., \& Weisburd, D. (1994). Diffusion of Crime Control Benefits: Observations on the Reverse of Displacement. Crime Prevention Studies, 2, 165-184.

Cochrane, W. G., \& Cox, G. M. (1957). Experimental Designs (Second). John Wiley \& Sons.

Cohen, J. (2013). Statistical Power Analysis for the Behavioral Sciences. Routledge.

Cook, T. D., Campbell, D. T., \& Day, A. (1979). Quasi-Experimentation: Design \& Analysis Issues for Field Settings (Vol. 351). Houghton Mifflin Boston.

Cross, R. (1998). The Sweet Spot of a Baseball Bat. American Journal of Physics, 66(9), 772-779.

Curtis-Ham, S., \& Walton, D. (2017). The New Zealand Crime Harm Index: Quantifying Harm Using Sentencing Data. 13.

Department of Corrective Services, G. of W. A. (2016). Young People in the Justice System: A Review of the Young Offenders Act 1994 (p. 71).

Dilmé, F., \& Garrett, D. F. (2018). Residual Deterrence. Journal of the European Economic Association. https://doi.org/10.1093/jeea/jvy034

Fienberg, S., Larntz, K., \& Reiss, A. J. (1980). Redesigning the Kansas City Preventive Patrol Experiment. Evaluation, 3(1-2), 124-131.

Gibson, C., Slothower, M., \& Sherman, L. W. (2017). Sweet Spots for Hot Spots? A CostEffectiveness Comparison of Two Patrol Strategies. Cambridge Journal of Evidence-Based Policing, 1(4), 225-243.

Grogger, J. (1990). The Deterrent Effect of Capital Punishment: An Analysis of Daily Homicide Counts. Journal of the American Statistical Association, 85(410), 295-303. 
Haberman, C. P. (2016). A view inside the "black box" of hot spots policing from a sample of police commanders. Police Quarterly, 19(4), 488-517.

House, P. D., \& Neyroud, P. W. (2018). Developing a Crime Harm Index for Western Australia: The WACHI. Cambridge Journal of Evidence-Based Policing, 2(1-2), 70-94. https://doi.org/10.1007/s41887-018-0022-6

Kleiman, M. (1987). Crackdowns: The Effects of Intensive Enforcement on Retail Heroin Dealing. In M. R. Chaiken (Ed.), Street Level Drug Enforcement: Examining the Issues. National Institute of Justice.

Koper, C. S. (1992). The Deterrent Effects of Police Patrol Presence upon Criminal and Disorderly Behavior at Hot Spots of Crime. Annual Meeting of the American Society of Criminology, New Orleans, Louisiana.

Koper, C. S. (1995). Just Enough Police Presence: Reducing Crime and Disorderly Behavior by Optimizing Patrol Time in Crime Hot Spots. Justice Quarterly, 12(4), 649-672. https://doi.org/10.1080/07418829500096231

Koper, C. S., Taylor, B. G., \& Woods, D. J. (2013). A randomized test of initial and residual deterrence from directed patrols and use of license plate readers at crime hot spots. Journal of Experimental Criminology, 9(2), 213-244. https://doi.org/10.1007/s11292-012-9170-z

Makinen, T., \& Takala, H. (1980). The 1976 Police Strike in Finland. Scandanvian Studies in Criminology, 7(1), 87-106.

Marciniak, E. M. (1995). Community Policing of Domestic Violence: Neighborhood Differences in the Effect of Arrest.

Martin, W. (2017). Unequal Justice for Indigenous Australians. Criminal Lawyers’ Association of the Northern Territory Biennial Conference, Bali, Indonesia.

Matsueda, R. L., Kreager, D. A., \& Huizinga, D. (2006). Deterring Delinquents: A Rational Choice Model of Theft and Violence. American Sociological Review, 71(1), 95-122. https://doi.org/10.1177/000312240607100105 
Nagin, D. S. (1998). Criminal Deterrence Research at the Outset of the Twenty-First Century. Crime and Justice, 23, 1-42.

Nagin, D. S. (2013). Deterrence in the Twenty-First Century. Crime and Justice, 42(1), 199-263.

Nagin, D. S., \& Sampson, R. J. (2019). The Real Gold Standard: Measuring Counterfactual Worlds that Matter Most to Social Science and Policy. Annual Review of Criminology.

National Academies of Sciences, E. (2018). Proactive Policing: Effects on Crime and Communities. National Academies Press.

Oatley, G., Williams, S., Barnes, G. C., Clare, J., \& Chapman, B. (2019). Crime Concentration in Perth CBD: A Comparison of Officer Predicted Hot Spots, Data Derived Hot Spots and Officer GPS Patrol Data. Australian Journal of Forensic Sciences. https://doi.org/10.1080/00450618.2019.1569141

Pate, A. M., \& Hamilton, E. E. (1992). Formal and Informal Deterrents to Domestic Violence: The Dade County Spouse Assault Experiment. American Sociological Review, 57(5), 691. https://doi.org/10.2307/2095922

Ratcliffe, J. H. (2015). Towards an Index for Harm-Focused Policing. Policing, 9(2), 164-182. https://doi.org/10.1093/police/pau032

Ratcliffe, J. H., Taniguchi, T., Groff, E. R., \& Wood, J. D. (2011). The Philadelphia Foot Patrol Experiment: A Randomized Controlled Trial of Police Patrol Effectiveness in Violent Crime Hotspots. Criminology, 49(3), 795-831.

Reiss, A. J. (1971). The Police and the Public (Vol. 39). Yale University Press.

Rosenfeld, R., Deckard, M. J., \& Blackburn, E. (2014). The Effects of Directed Patrol and SelfInitiated Enforcement on Firearm Violence: A Randomized Controlled Study of Hot Spot Policing. Criminology, 52(3), 428-449.

Ross, H. L. (1982). Deterring the drinking driver. 
Salmon, P. M., Walker, G. H., \& Stanton, N. A. (2016). Pilot error versus sociotechnical systems failure: A distributed situation awareness analysis of Air France 447. Theoretical Issues in Ergonomics Science, 17(1), 64-79. https://doi.org/10.1080/1463922X.2015.1106618

Sampson, R. J., Winship, C., \& Knight, C. (2013). Translating Causal Claims: Principles and Strategies for Policy-Relevant Criminology. Criminology \& Public Policy, 12, 587.

Sherman, L. W. (1990). Police Crackdowns: Initial and Residual Deterrence. Crime and Justice, 12, $1-48$.

Sherman, L. W., Gartin, P. R., \& Buerger, M. E. (1989). Hot Spots of Predatory Crime: Routine Activities and the Criminology of Place. Criminology, 27(1), 27-56.

Sherman, L. W., Neyroud, P. W., \& Neyroud, E. (2016). The Cambridge Crime Harm Index: Measuring Total Harm from Crime Based on Sentencing Guidelines. Policing, 10(3), 171183. https://doi.org/10.1093/police/paw003

Sherman, L. W., Rogan, D. P., Edwards, T., Whipple, R., Shreve, D., Witcher, D., Trimble, W., Velke, R., \& Blumberg, M. (1995). Deterrent Effects of Police Raids on Crack Houses: A Randomized, Controlled Experiment. Justice Quarterly, 12(4), 755-781.

Sherman, L. W., Smith, D. A., Schmidt, J. D., \& Rogan, D. P. (1992). Crime, Punishment, and Stake in Conformity: Legal and Informal Control of Domestic Violence. American Sociological Review, 57(5), 680. https://doi.org/10.2307/2095921

Sherman, L. W., \& Weisburd, D. (1995). General Deterrent Effects of Police Patrol in Crime "Hot Spots": A Randomized, Controlled Trial. Justice Quarterly, 12(4), 625-648.

Sizer, J., \& van Smeerdijk, J. (2017). Indigenous Incarceration: Unlock the Facts (p. 94). PwC Indigenous Consulting.

Sorg, E. T., Haberman, C. P., Ratcliffe, J. H., \& Groff, E. R. (2013). Foot Patrol in Violent Crime Hot Spots: The Longitudinal Impact of Deterrence and Posttreatment Effects of Displacement. Criminology, 51(1), 65-101. https://doi.org/10.1111/j.1745-

9125.2012.00290.x 
Taylor, B., Koper, C. S., \& Woods, D. J. (2011). A randomized controlled trial of different policing strategies at hot spots of violent crime. Journal of Experimental Criminology, 7(2), 149-181. https://doi.org/10.1007/s11292-010-9120-6

Telep, C. W., Mitchell, R. J., \& Weisburd, D. (2014). How Much Time Should the Police Spend at Crime Hot Spots? Answers from a Police Agency Directed Randomized Field Trial in Sacramento, California. Justice Quarterly, 31(5), 905-933.

https://doi.org/10.1080/07418825.2012.710645

Weisburd, D. (2015). The Law of Crime Concentration and the Criminology of Place. Criminology, 53(2), 133-157. https://doi.org/10.1111/1745-9125.12070

Weisburd, D., \& Green, L. (1995). Policing drug hot spots: The Jersey City drug market analysis experiment. Justice Quarterly, 12(4), 711-735.

Weisburd, D., Wooditch, A., Weisburd, S., \& Yang, S.-M. (2016). Do Stop, Question, and Frisk Practices Deter Crime?: Evidence at Microunits of Space and Time. Criminology \& Public Policy, 15(1), 31-56. https://doi.org/10.1111/1745-9133.12172

Whyte, W. F. (1947). Street Corner Society: The Social Structure of an Italian Slum. University of Chicago Press.

Wikström, P. O. H., Oberwittler, D., Treiber, K., Hardie, B., Wikström, P. O. H., Oberwittler, D., Treiber, K., \& Hardie, B. (2012). The Peterborough Adolescent and Young Adult Development Study. Oxford University Press Oxford.

Williams, S., \& Coupe, T. (2017). Frequency vs. Length of Hot Spots Patrols: A Randomised Controlled Trial. Cambridge Journal of Evidence-Based Policing, 1(1), 5-21. https://doi.org/10.1007/s41887-017-0003-1

Zimring, F. E., \& Hawkins, G. J. (1973). Deterrence: The Legal Threat in Crime Control. University of Chicago Press. 


\section{APPENDIX}

TABLE A.1. Comparison of Bicycle and Automotive Patrolling

Effect

\begin{tabular}{lrrrr} 
& Bicycles & Cars & $p^{\text {a }}$ & Size $^{\mathrm{b}}$ \\
\hline Speeds recorded during active patrol & & & & \\
Raw sample size (GPS pings on active patrol) & $1.15 \mathrm{M}$ & $1.73 \mathrm{M}$ & & \\
Weighted sample size (hours of speed data) & $1,686.7$ & $2,734.9$ & & \\
Mean instantaneous speed per unit of time $(\mathrm{km} / \mathrm{h})$ & 5.5 & 19.6 & $<.001^{*}$ & -0.76 \\
Proportion of time at stationary speed $(<1 \mathrm{~km} / \mathrm{h})$ & $54.8 \%$ & $39.7 \%$ & $<.001^{*}$ & 0.30 \\
Proportion of time at pedestrian speed $(1-8 \mathrm{~km} / \mathrm{h})$ & $28.9 \%$ & $11.4 \%$ & $<.001^{*}$ & 0.45 \\
Proportion of time at bicycle speed $(8-30 \mathrm{~km} / \mathrm{h})$ & $10.9 \%$ & $17.7 \%$ & $<.001^{*}$ & -0.19 \\
Proportion of time at automotive speed $(\geq 30 \mathrm{~km} / \mathrm{h})$ & $5.4 \%$ & $31.2 \%$ & $<.001^{*}$ & -0.72
\end{tabular}

5-30 Minute Patrols in Randomly-Assigned Hot Spots

Sample size (location-days)

$525 \quad 800$

Mean patrols delivered per location-day

$0.63 \quad 0.70$

.251

$-0.07$

Mean minutes of patrol presence per location-day

11.06

11.09

.976

0.00

Outcome Measures

Proportion of location-days with at least one offence

$\begin{array}{llll}10.9 \% & 10.3 \% & .726 & 0.02\end{array}$

Mean offences reported per location-day

$\begin{array}{lll}0.151 & 0.143 \quad .778\end{array}$

0.02

Mean crime-harm of offences (outliers removed) ${ }^{\mathrm{c}}$

0.865

1.833

.322

$-0.05$

Proportion of location-days with requested CAD tasking

$26.5 \%$

$24.1 \%$

.338

0.02

Mean CAD tasks requested per location-day

0.373

0.343

.449

0.04

Mean minutes of tasking attended (outliers removed) ${ }^{\mathrm{d}}$

17.167

12.718

.171

0.08

\footnotetext{
${ }^{\mathrm{a}}$ Two-tailed t-tests, assuming unequal variances

${ }^{\mathrm{b}}$ Cohen's $h$ for comparisons of proportions, Cohen's $d$ for all other comparisons

${ }^{c}$ Excludes any offences where the crime-harm value exceeds three years (1,096 days) of incarceration

${ }^{\mathrm{d}}$ Excludes any dispatch tasking where the job was attended for more than 12 hours

$* p<.05$
} 
TABLE A.2. Mean Daily Duration of 5-30 Minute Patrolling at Specific Hotspot

Locations

\begin{tabular}{lrrrr}
\hline & & & & Effect \\
& Treatment & Control & $p^{\mathrm{a}}$ & Size $^{\mathrm{b}}$ \\
\hline Location A (Rail station) & 36.13 & 16.85 & $<.001^{*}$ & 0.64 \\
Location B (Fast food) & 23.76 & 7.89 & $<.001^{*}$ & 0.94 \\
Location C (Rail station) & 19.83 & 4.04 & $<.001^{*}$ & 1.03 \\
Location D (Shopping) & 16.70 & 3.35 & $<.001^{*}$ & 0.92 \\
Location E (Shopping) & 13.04 & 2.04 & $<.001^{*}$ & 0.78 \\
Location F (Pub/Hotel) & 10.66 & 1.35 & $<.001^{*}$ & 0.77 \\
Location G (Shopping) & 9.96 & 1.33 & $<.001^{*}$ & 0.72 \\
Location H (Shopping) & 9.68 & 1.19 & $<.001^{*}$ & 0.75 \\
Location I (Near large shopping centre) & 10.27 & 0.97 & $<.001^{*}$ & 0.83 \\
Location J (Rail station) & 9.94 & 0.77 & $<.001^{*}$ & 0.86 \\
Location K (Residential intersection) & 9.34 & 0.74 & $<.001^{*}$ & 0.77 \\
Location L (Residential intersection) & 9.99 & 0.62 & $<.001^{*}$ & 0.91 \\
Location M (Residential intersection) & 8.08 & 0.60 & $<.001^{*}$ & 0.76 \\
Location N (Rail station) & 10.93 & 0.54 & $<.001^{*}$ & 0.91 \\
Location O (Residential intersection) & 9.13 & 0.10 & $<.001^{*}$ & 0.81 \\
\hline
\end{tabular}

${ }^{\mathrm{a}}$ Two-tailed t-tests, assuming unequal variances

${ }^{\mathrm{b}}$ Cohen's $d$ 


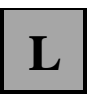

1 kilometer

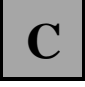

E

$\mathbf{K}$

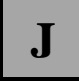

G

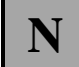

D

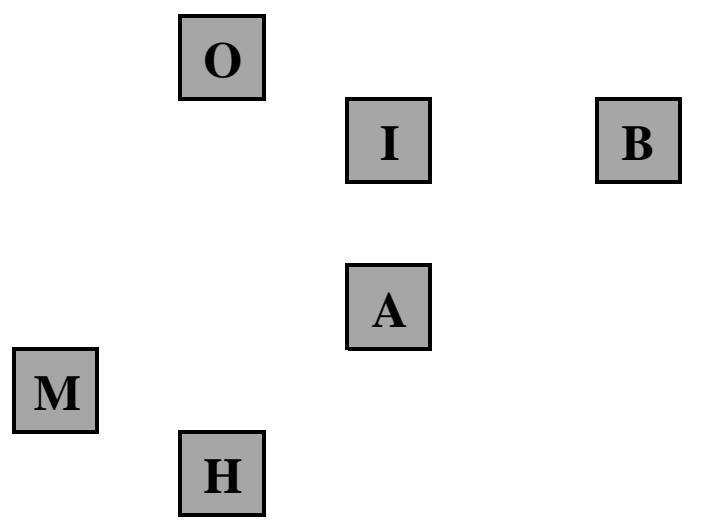

FIGURE A.1: Grid map of the 15 participating hot spots, as identified in Table A.2 


\section{AUTHOR BIOGRAPHIES:}

Geoffrey C. Barnes is the Deputy Director of Strategic Insight for the London Metropolitan Police Service and an Affiliated Lecturer in Applied Criminology and Police Management at the University of Cambridge. At the time of this research, he was the inaugural Director of Criminology for the Western Australia Police Force. His work includes numerous randomised controlled trials in policing and community corrections and the use of algorithmic forecasting to predict criminal reoffending and road traffic collisions.

Simon Williams is incapable of writing an author bio, and hopes that the rest of the world pays no attention to him. He enjoys playing team sports in which he pretends to have amputated his arms. He used to reside in Western Australia, but then thought better of it after he read some of the lies that appear in the acknowledgement section of this paper. He has since moved to a small island in the South Pacific.

Lawrence W. Sherman is Director of Research at the Jerry Lee Centre of Experimental Criminology at the University of Cambridge Institute of Criminology and Director of the Cambridge Centre for Evidence-Based Policing. He has designed or led over 40 randomized field experiments in policing and justice, on subjects including arrests for domestic abuse and police-led restorative justice conferences. His theoretical work includes defiance theory and residual deterrence. He is also the founding Editor of the Cambridge Journal of Evidence-Based Policing.

Jesse Parmar is an analyst within the WA Police Force's Office of Applied Criminology (OAC). He holds a Bachelor of Economics (Honours) from the University of Western Australia, where he wrote a dissertation on educational economics. In his time at the Office of Applied Criminology, Jesse has had 
the opportunity to work on a range of experiments, with a particular focus of hot spot policing evaluations and proactive police engagement with the community.

Paul House is a data analyst within the WA Police Office of Applied Criminology. Paul manages a team of analysts, interns and graduates who conduct analysis for their evidence-based experiments. He recently completed the Master of Studies degree in Applied Criminology and Police Management at the University of Cambridge. Paul holds a BSc(Aviation), has worked as a general aviation flying instructor and as a geospatial intelligence analyst for the Australian Department of Defence.

Stephen A. Brown is the former Deputy Commissioner of the Western Australia Police and Chair of the Australia and New Zealand Society of Evidenced Based Policing. He is recognized for creating the first Evidenced Based Policing Division within an Australian police agency, along with an internal authorizing environment which enables research into policing to be undertaken. 